\title{
الوأد عند العرب قبل الاسلام
}

\section{م.د. واثقه حازمر جاسه الحيالي \\ وزارة التربية / الملديرية العامة لتربية نينوى}

drwathiqaalhayali2020@gmail.com

DOI: https://doi.org/10.36473/ujhss.v60i4.1832

تاريخ الاستلام : 15/ 12 12/ 2020

تاريخ القبول : 19 / 1 / 2021 :

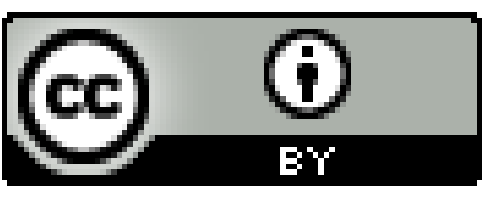

This work is licensed under a Creative Commons Attribution 4.0 International License

المستخلص

تعد ظاهرة وأد البنات من الظواهر السلبية واللاإنسانية وسوف نسلط الضوء على الاسباب

التي دفعت بعض بطون القبائل العربية الى وأد بناتها او حتى قتل اولادها ومن القبائل التي كانت تأد البنات هي ربيعة وكندة وتميم وبعض بطون قريش • والملاحظ أن المجتمع العربي قبيل

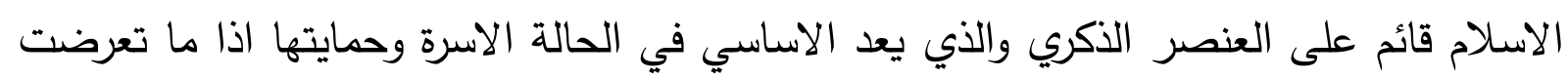

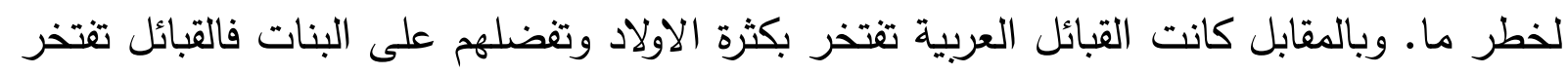

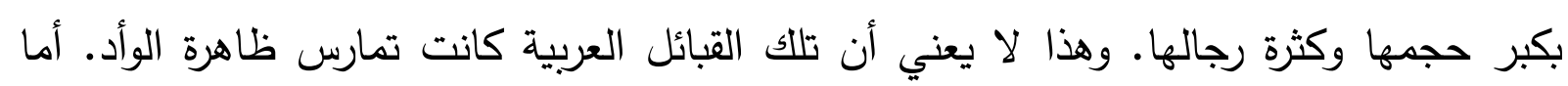

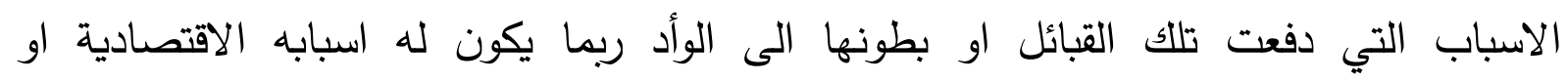
الاجتماعية او السياسية والتي كانت السبب الى هذه الظاهرة الا وهي الوأد.

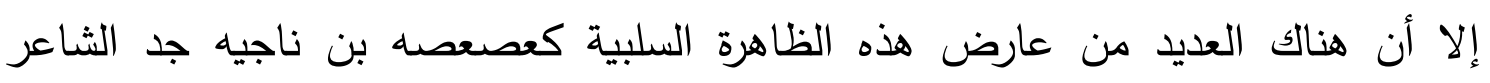

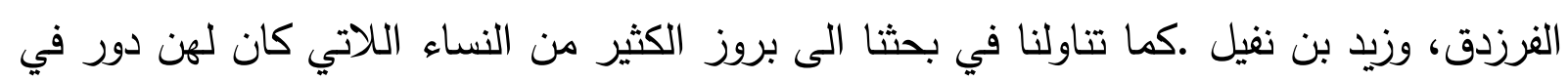

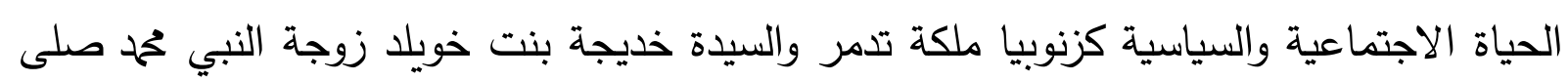
الله عليه وسلم. الكلمات المفتاحية : الوأد، قبائل , انتساب , قبل الاسلام , اسباب 


\section{Infanticide among the Arabs before Islam}

\section{Inst. Wathiqa Hazim Jasim (Ph.D) \\ Ministry of Education Directorate General of Nineveh Education drwathiqaalhayali2020@gmail.com}

\section{Abstract}

The phenomenon of infanticide of girls is a negative and inhuman phenomenon and we will highlight the reasons that led some Arab tribes to infant their daughters or even kill their children and from the tribes that used to do this to infant the girls are Rabia, Kinda, Tamim and some Quraysh tribes. It should be noted that the Arab society before Islam is based on the male element, which is the main condition of the family and its protection if it is exposed to a threat. On the other hand, The Arab tribes were proud of the large number of boys and preferred them to girls. This does not mean that these Arab tribes were practicing the phenomenon of infanticide. The reasons that led these tribes or their origins to kill may have economic, social or political reasons, which were the cause of this phenomenon, namely, infanticide.

However, there are many opponents of this negative phenomenon, such as Saesaa, ben Najia, grandfather of the poet Al-Farazdaq, and Zaid ben Nophil. In our research, we also address the emergence of many women who had a role in the social and political life of Zenobia, queen of Tadmur, and Ms. Khadija Bint Khoeld, wife of the Prophet Muhammad (Peace be on him).

Keywords: Infanticide of girls, Tribes, Affiliation, Pre-Islamic, Reasons.

$$
\text { اولاً: الاسرة وتكوينها الاجتماعي قبل الاسلام }
$$

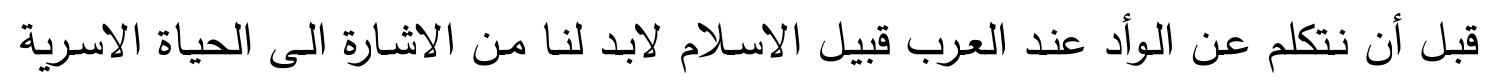

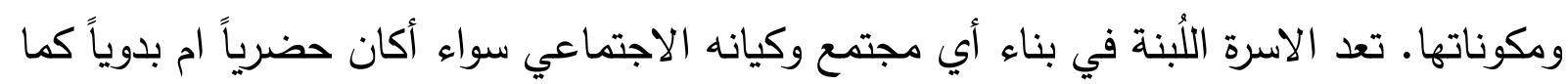

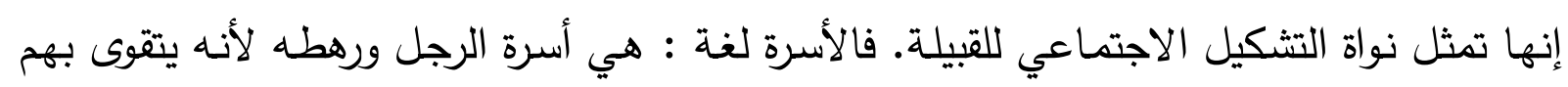

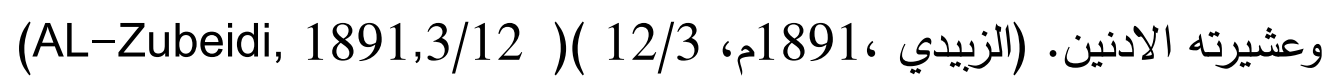
اما الاسرة اصطلاحا : تعني البيت الذي يسكنه أفرادها وقد تشمل فضلاً عن الأب والأم والأبناء

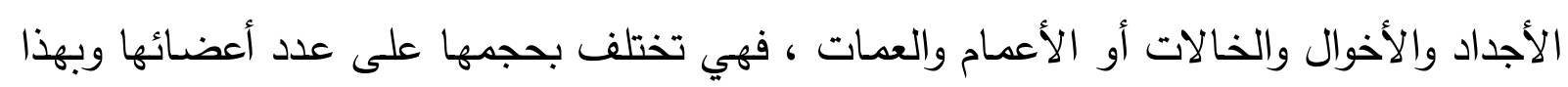

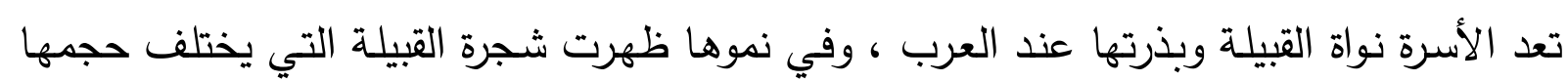


وكثرة أغصانها وفروعها باختلاف منبت الثجرة والظروف والعوامل التي أثرت في تكوينها من بذرة

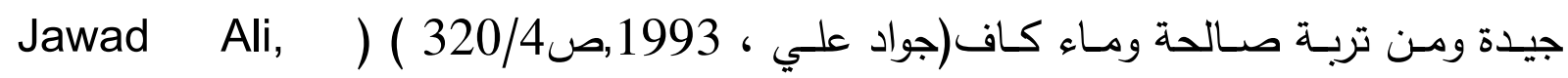
. (1993,p,4/320

يقوم التنظيم الاسري في المجتمع العربي على اساس النظام الابوي اذ تبوأ الرجل فيه مركز

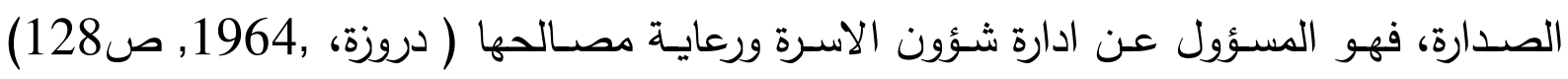

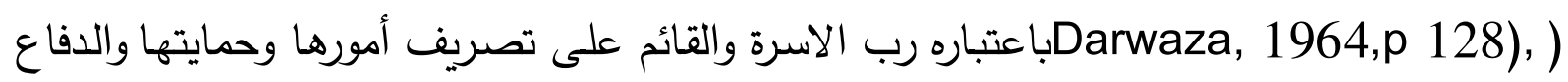

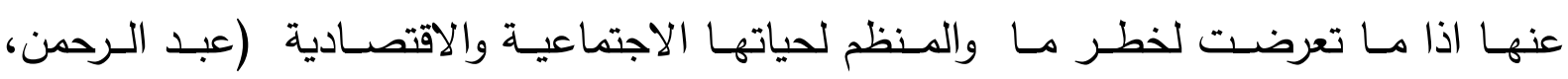
(48 Abdul Rahman, 1987, p)( 48 (د) 1987

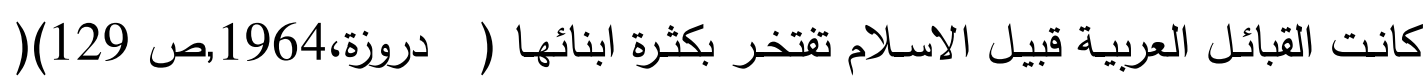

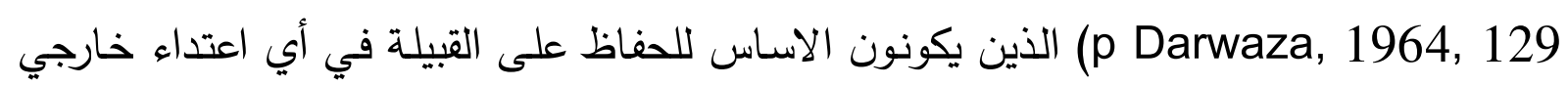

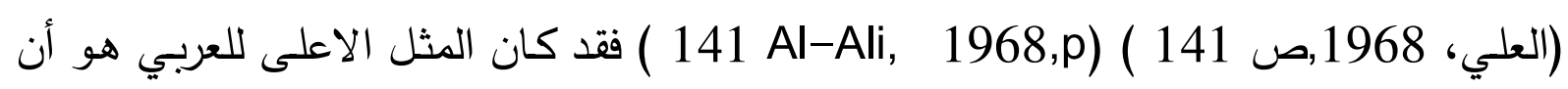
تنجب المرأة اكبر عدد من الابناء لكي ترتفع مكانته بين ابناء قومه حيث كان العرب يتفاخرون

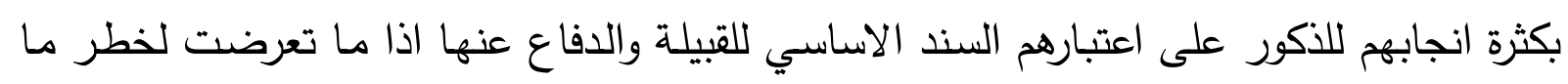
(دروزة،1964,ص 129 - 130 -130 (130)( Darwaza, 1964,p) لقد عاشت المرأة في المجتمع قبيل الاسلام بين جانبين متتاقضين فقد تفاوتت مكانتها بين

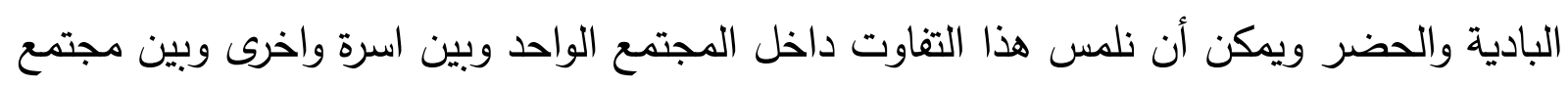

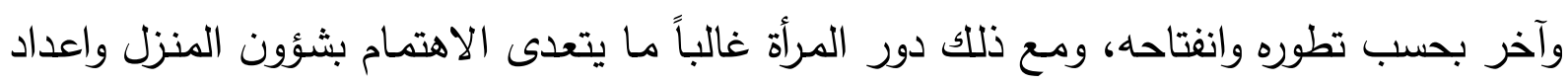
الطعام وتربية الاطفال والعناية بهم، وهي على العموم تابعة للرجل ومنسوبه اليها(دروزة، 1964

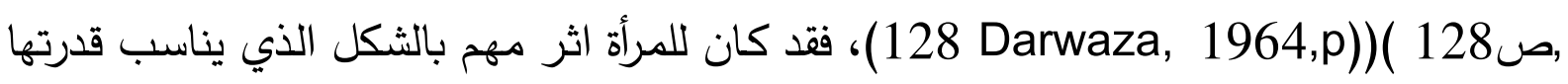
ومكانتها الاجتماعية (عبد الرحم،1987,ص 48 Abdul Rahman, 1987,p)( 48 (48).

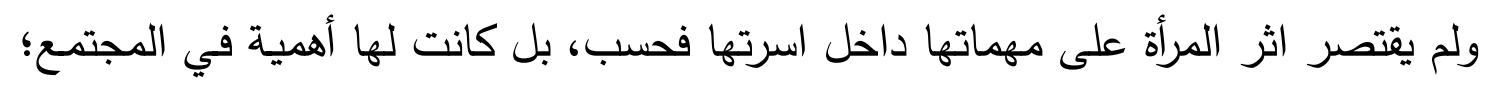

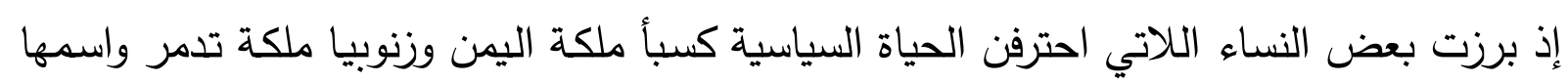
نائلة بنت عمرو بن الضروب بن حسان بن اذينة بن السميدع بن هير العمليقي (العماليق :

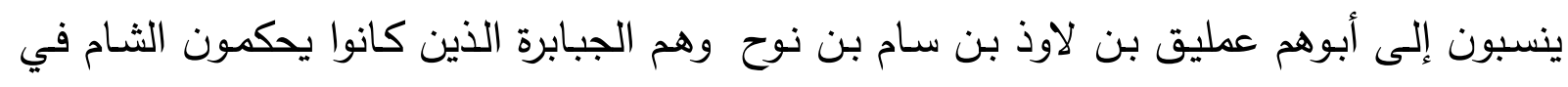

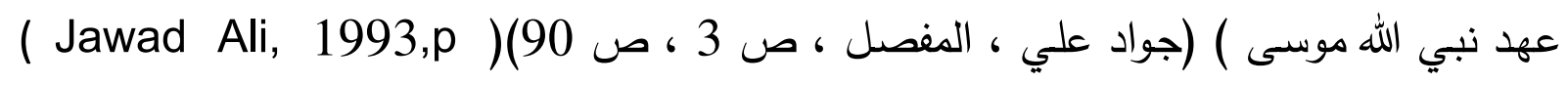
3/90 ـ وهي زوجة أذينة الثاني الذي تولى الحكم على تدمر سنة 258 م وعندما تولت زنوبيا الحكم على تدمر عقب مقتل زوجها سنة (266 م ) على شكل وصاية على ولدها ( وهب اللات ) ماتل 
الذي كان قاصـراً لذا فقد استأنفت سياسـة زوجها في التوسـع معتمدة على رجالها من العنصر العربي، واستطاعت هذه الملكة أن تكتب تاريخاً للشرق ، وقد أدركت بفطنتها السياسية إن أعداء

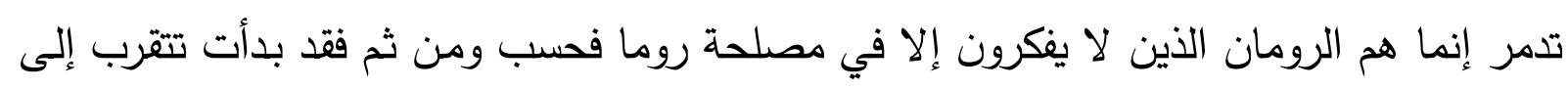
العناصر العربية المستوطنة في المدن القريبة فضلاً عن الأعراب التي كانت ترى أنهم عمادها في لإني

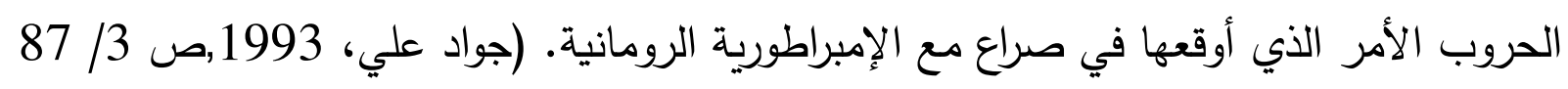
· (87/3 Jawad Ali, 1993,p)( لقد عملت ملكة تدمر على حكم البلاد وحافظت على مملكتها وشعبها وقد اظهرت قدرة فائقة في القتال والحروب بعد أن ادركت أن الرومان هم اعداء تدمر فأخذت تعمل على تكودين

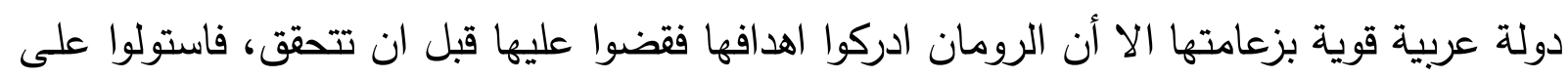
Jawad Ali, 1993,p)(جدمر وأزالوا ملكها ( توان 87/3_88). في حين نرى أن بعض النساء احترفن التجارة ونجحن في هذا المجال فبرزت نساء

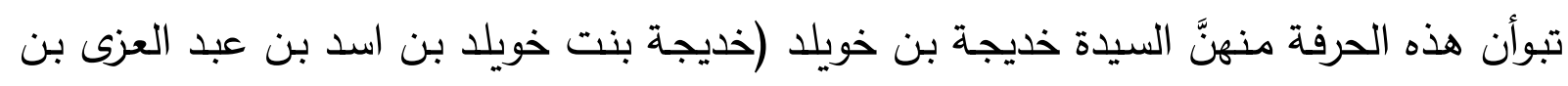
قصي بن كلاب بن حرة ولدت بمكة كانت ذا مال كثير وتجارة تبعث لها إلى الثام تستأجر الرجال

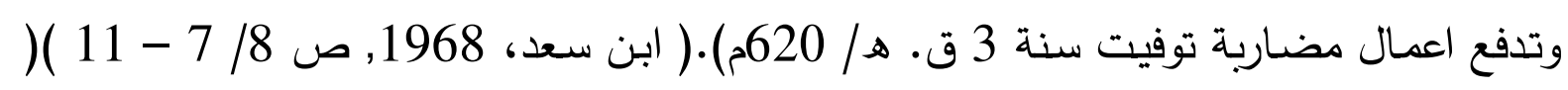

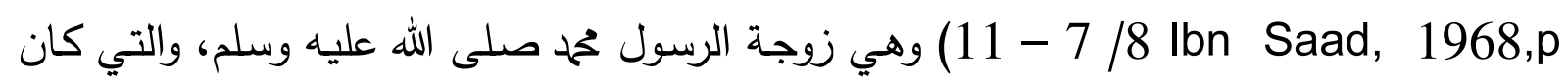

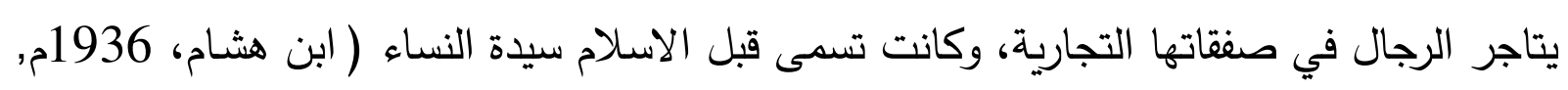

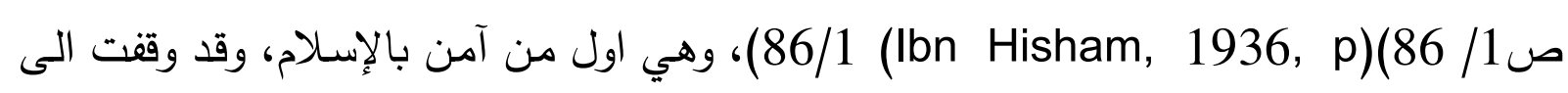

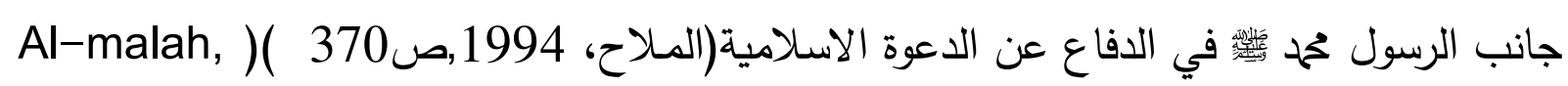
. (370 1994,p

ثانياً: الوأد عند العرب قبل الاسلام

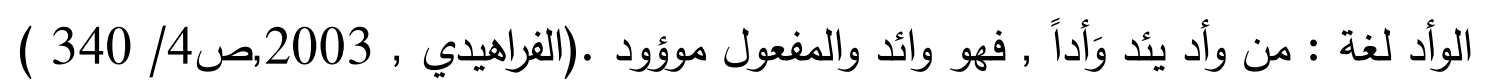

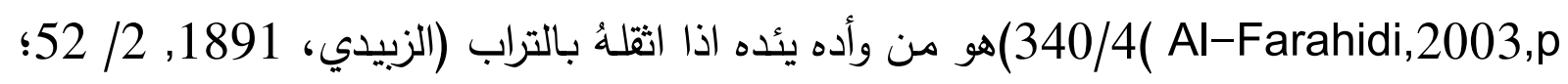
العسكري، ب. ت, ص 75 AL-Zubeidi, 1891, 2/52; Al-Askari , n.d , p)(

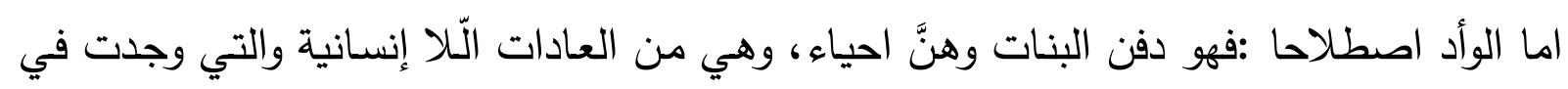

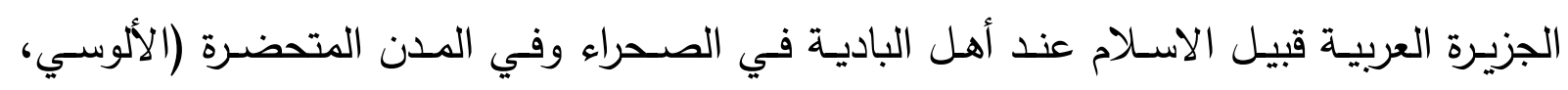

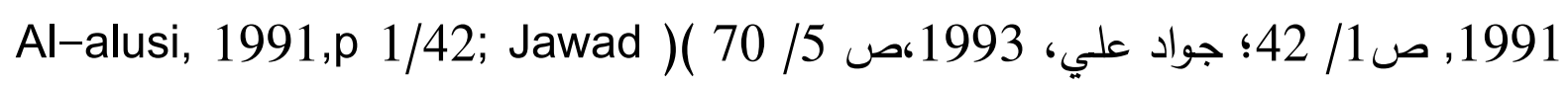


تعأن النظر إلى المرأة وليدة عوامل اجتماعية كثيرة، ومؤثرات بيئية معينة تعمل على تكوين العرف والتقاليد فتؤثر بدروها في المواقف تجاه المرأة وكانت لمكانة المرأة عند المداء

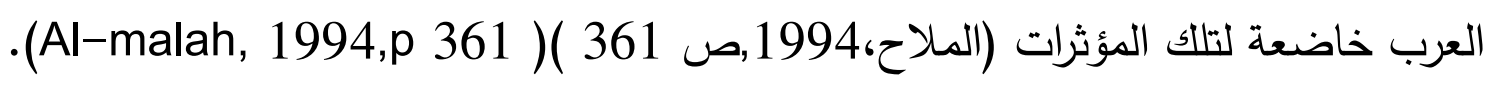
لقد تراوحت الاسباب التي دفعتهم الى ذلك بين ما هو اجتماعي واقتصادي وديني ـ فالبلنسية

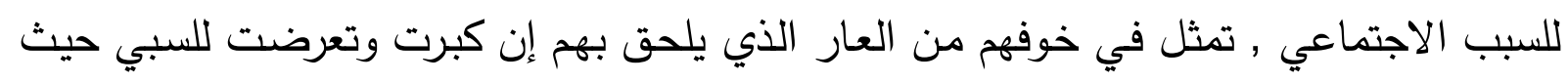

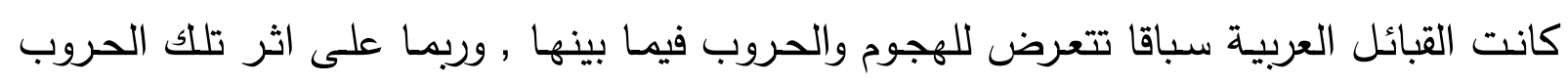

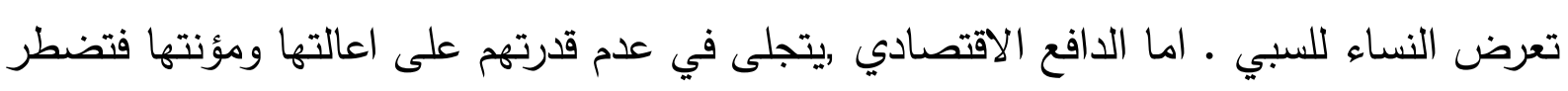

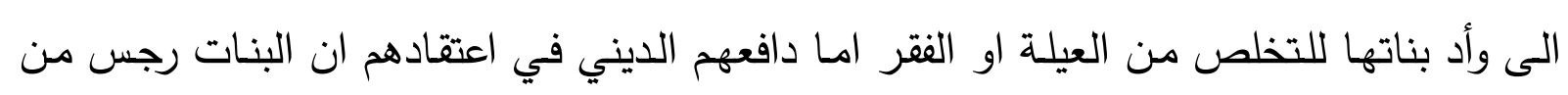

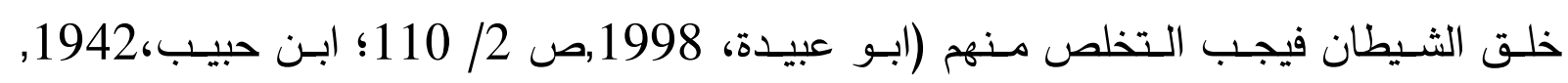

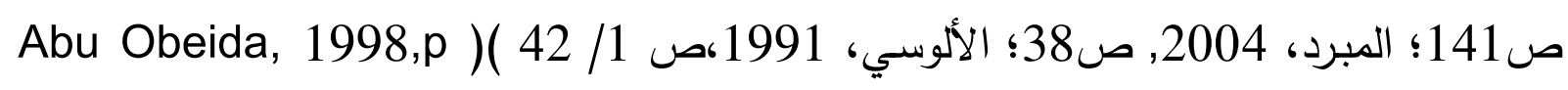
2/110; Ibn Habib, 1942,p 141; Al-mubrid, 2004,p 38; Alusi, 1991,p 42/1)، وقد ظلت هذه الظاهرة عند العرب حتى جاء الاسلام وحرمها وقد اشار القرآن الكريم اليها

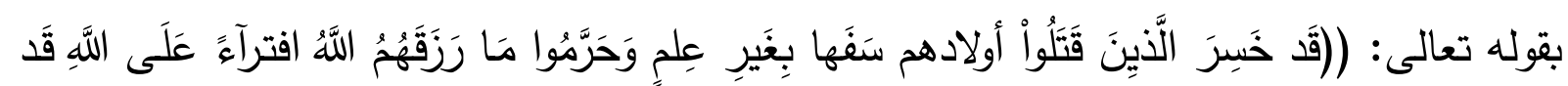

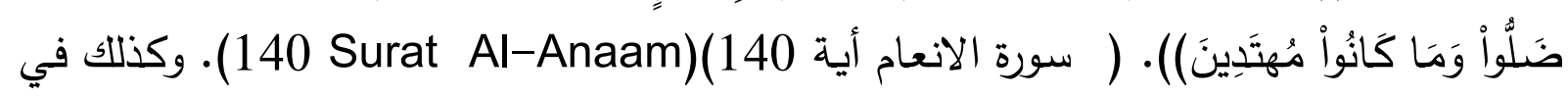

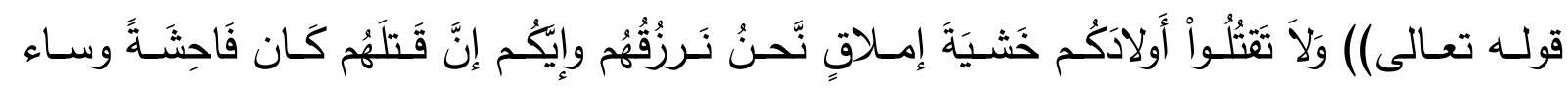

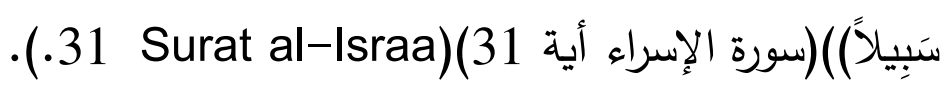
ويقول ( جواد علي,1993,ص 298/5 أنه لا يستبعد (298/5 Jawad Ali,1993,p)( وجود عوامل دينية قديمة هي التي حملت الجاهلين على الوأد وقتل الاولاد، من باب تقديم الضحايا

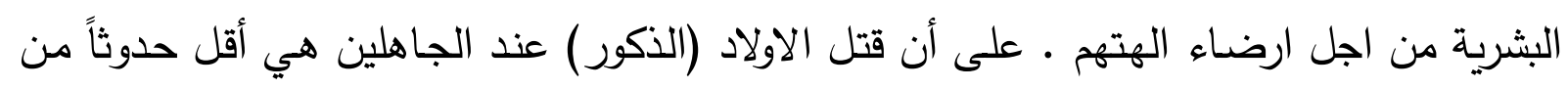

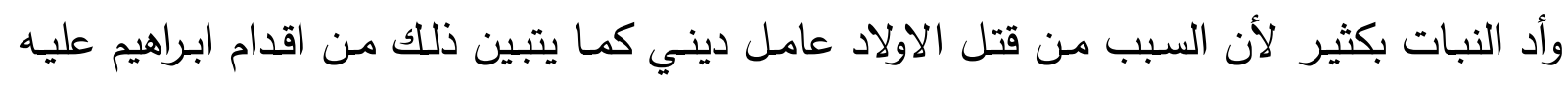

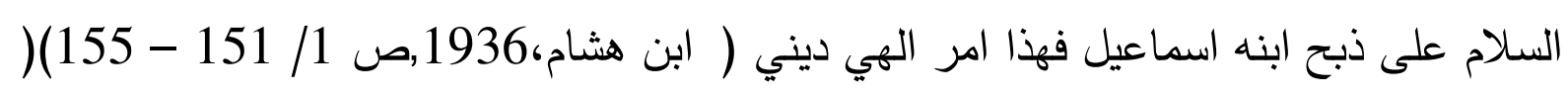
151/1 lbn Hisham, 1936,p استعصى عليه مطلب جليل فرج كربه او تحقيق مطلب لجأ الى تقديم احد ابنائه قرباناً للإلهة، كما فالها

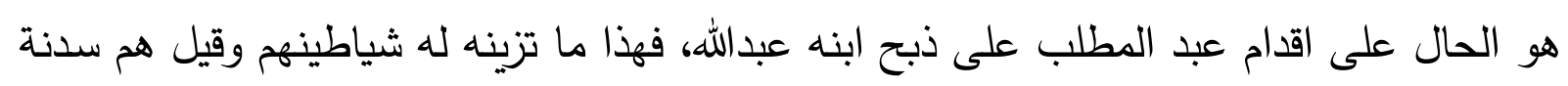

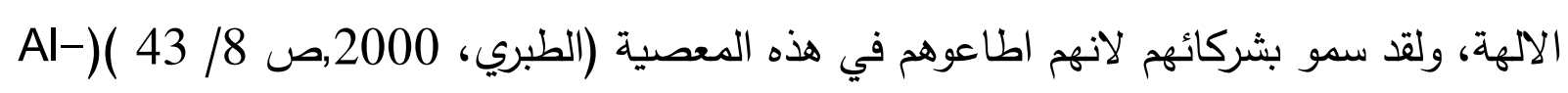

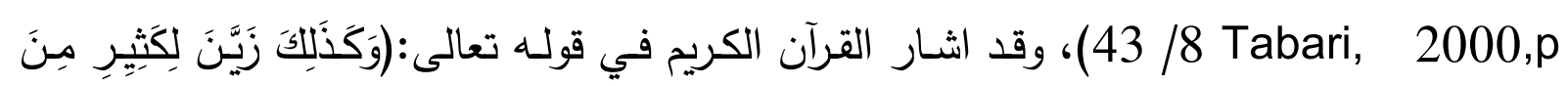

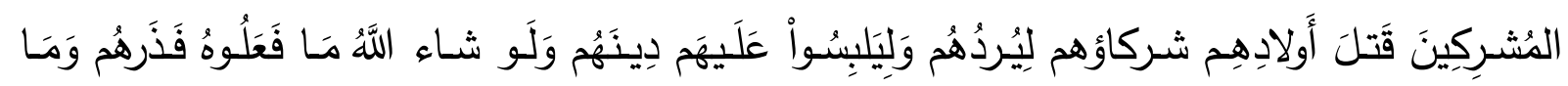


يَفَتَرُونَ )(سورة الانعام أية: 137)(137: Surat Al-Al anaam A).وربما يكون قتل الاولاد في تلك الفترة لا يختلف عن ظاهرة الوأد عند البنات وقد سبق ان ذكرنا الاسباب وقمنا بتعزيزها بالآيات القرآنية .

فإذا امعنـا في النظر في فترة مـا قبل الاسـلام وجدنا ظـاهرة وأد الاطفال كانت معروفة إنسة

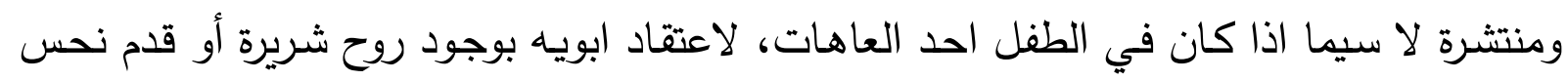

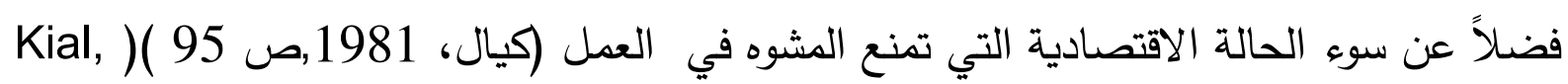
.(951981, p

إن قسوة حياة البداوة والصحراء قد ولدت ظاهرة وأد البنات وهي من الظواهر السلبية في

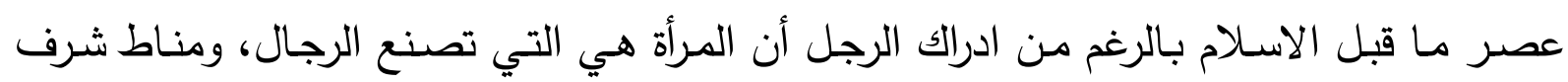

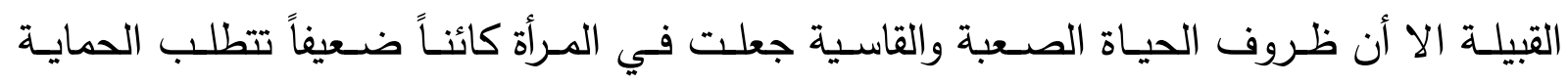

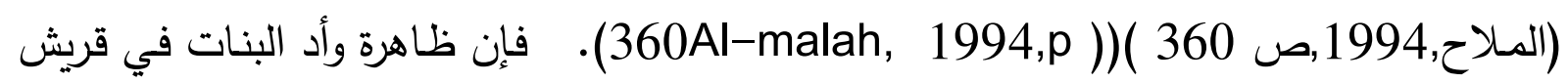
وفي غيرها من القبائل كقبيلة تميم , وأسد ، وهذيل، وبكر بن وائل.

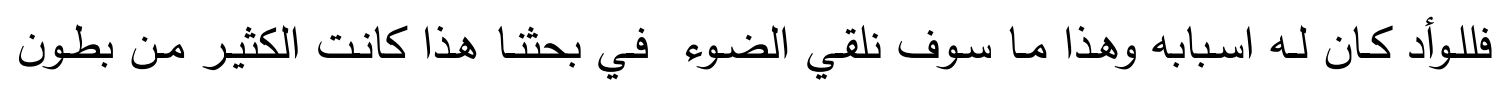

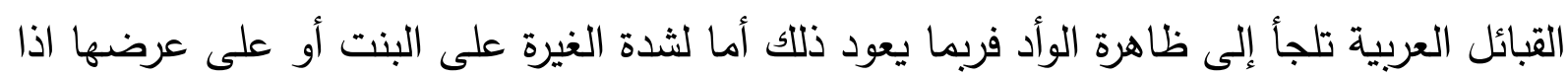

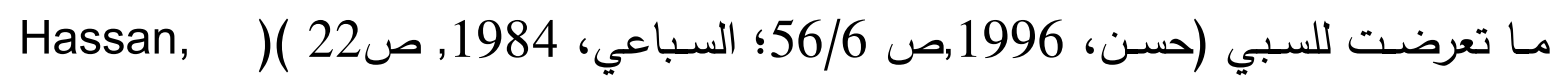
22 1996,p 6/56; Al-Sibai, 1984,p

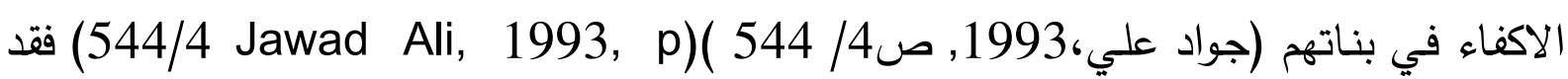

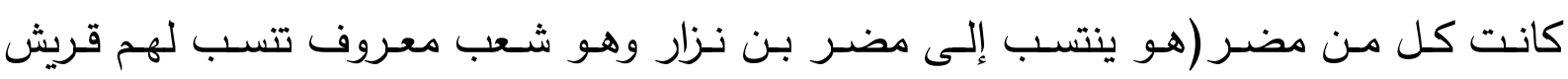

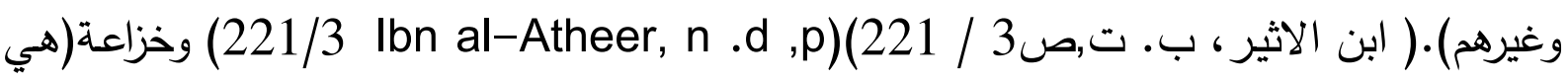

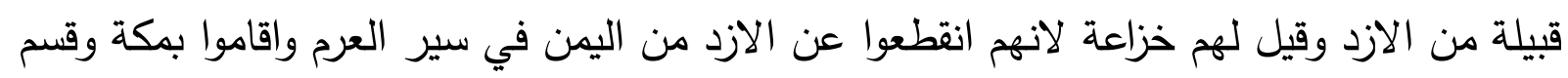

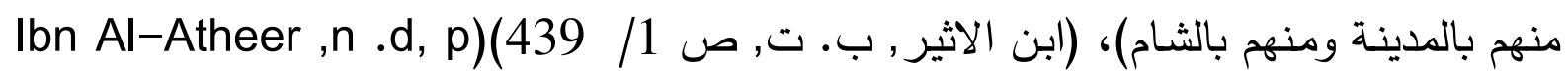

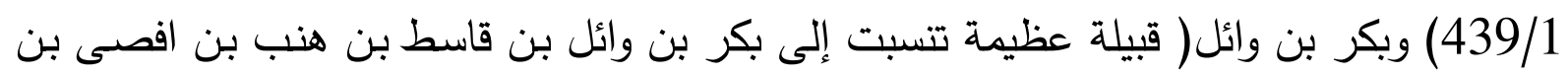

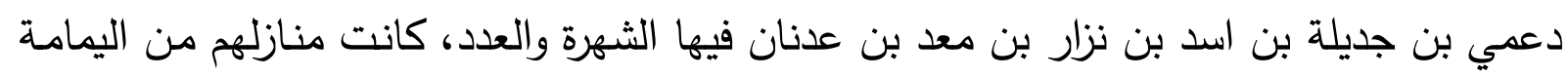

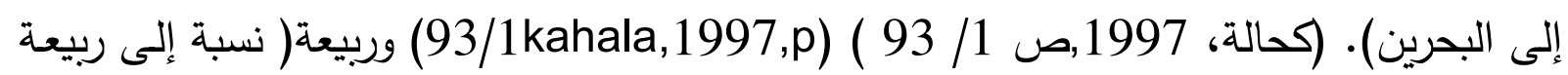
بن نزار وهي شعب عظيم فيه قبائل وبطون وأفخاذ وينتسب اليها بكر بن وائل بن قاسط). (ابن التبل

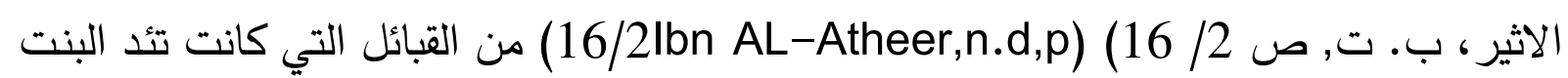


بسب كثرة الغارات التي تتعرض لها من قبل القبائل الاخرى بين فترة واخرى والتي كانت تعرف

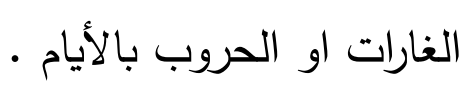
وكان اشد القبائل ممن كان الوأد البنات عندها هي قبيلة تميم (قبيلة تميم نسبة إلى تميم

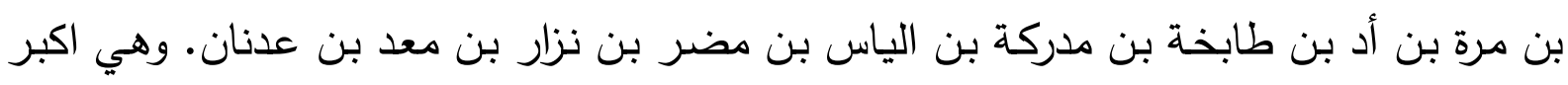

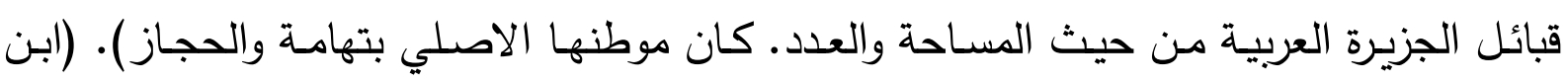

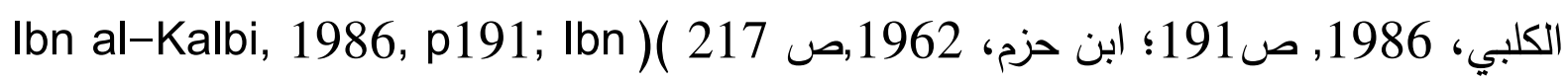
217 Hazm, 1962,p

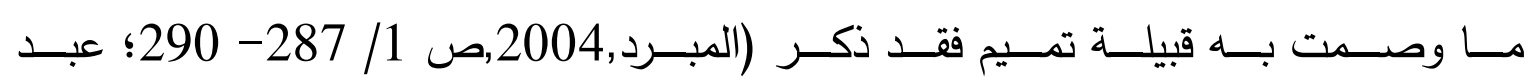
Al-mubrid,2004, p1/287-290; Abdul Rahman, 1987, (الرحمن,1987،ص 175) 175p

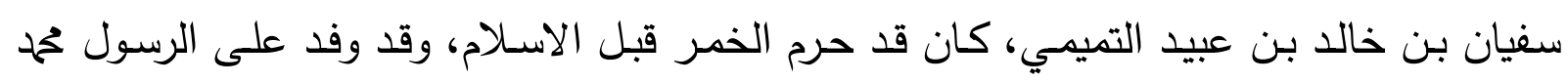

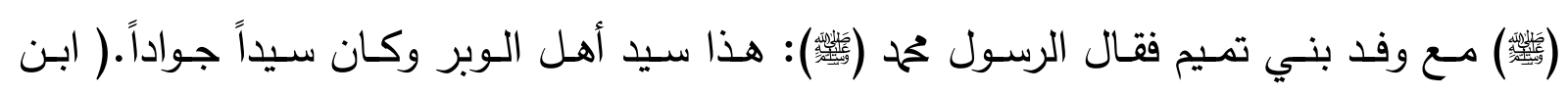

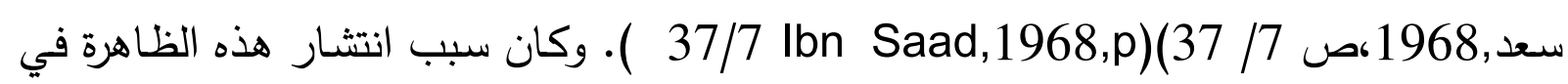

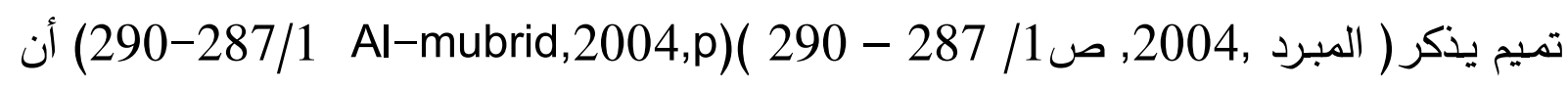
تميما منعت النعمان بن المنذر ( ابو قابوس، هو النعمان الثالث بن المنذر الرابع كان شهماً

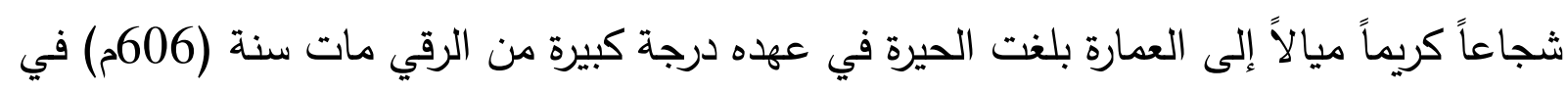
سجن كسرى ابرويز بخانقين ودفن في دير ابنته هند الصغرى).( ابن حبيب، (354 lbn Habib, 1942,p)(

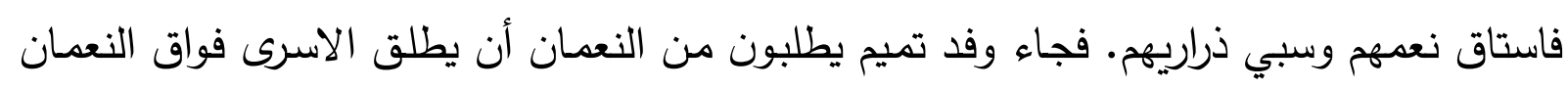

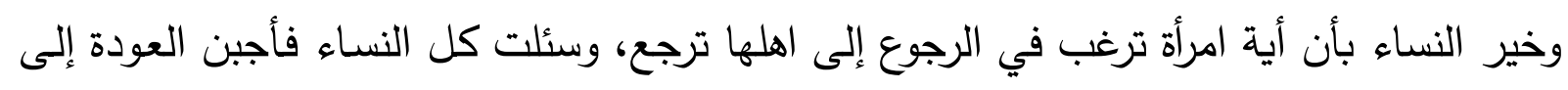

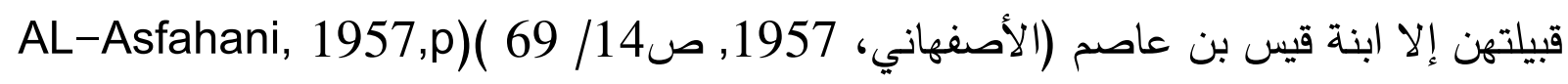

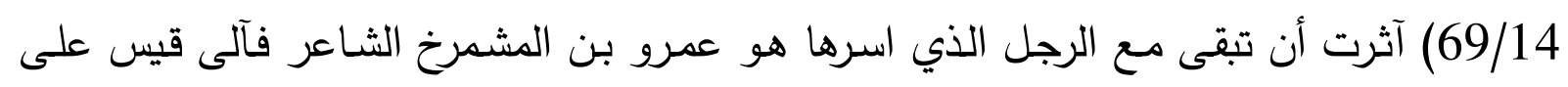

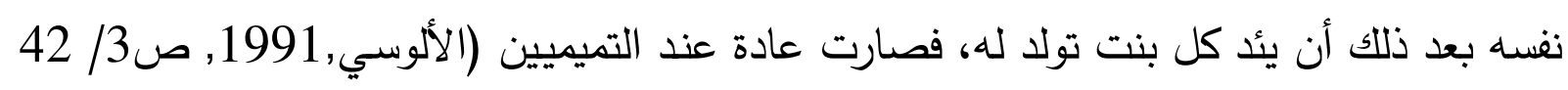
.(45-42/3 Al-Alusi,1991,p) ( 45 إلا أن كثيراً من عقلاء العرب لا يرضى بذللك، وكان منهم من يفتدي الموؤد من اهلها،

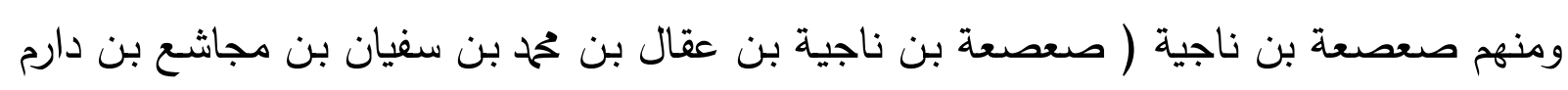

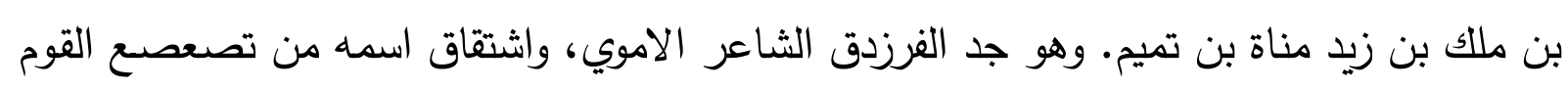


اذا تفرقوا، وكان صعصعة عظيم القدر ، يشتري المؤدات في الجاهلية، توفي سنة 9هـ 360م).

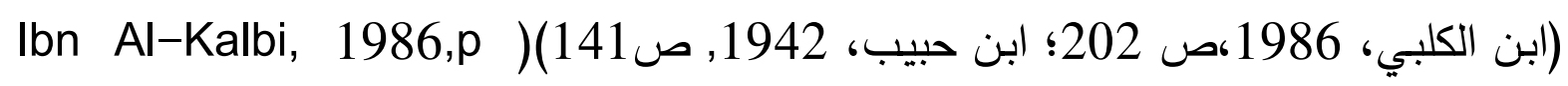
م 92 ) (141202; Ibn Habib, 1942, p (92lbn al-Jawzi, 2004, p

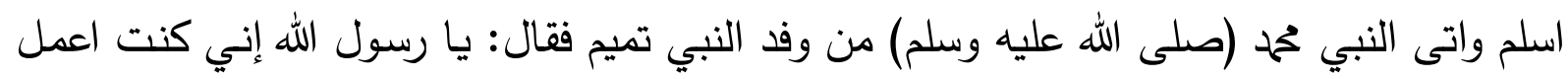

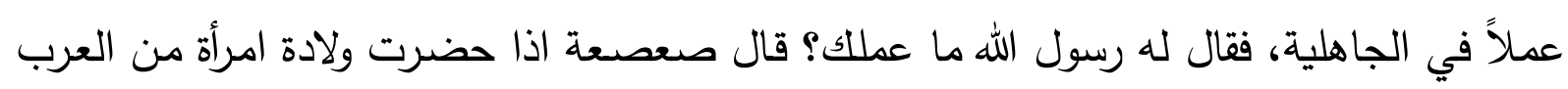

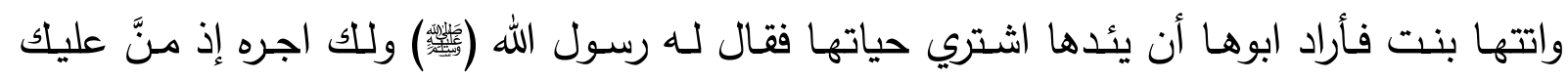

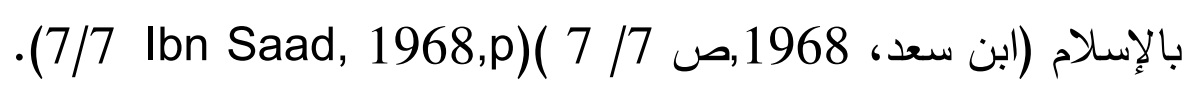

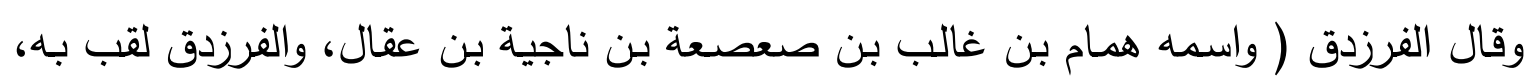

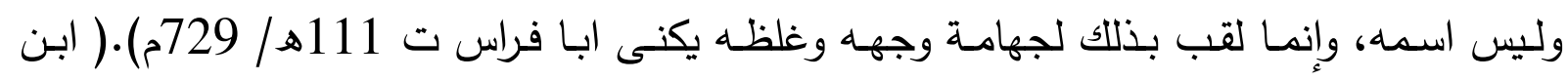
الكلبي، 1986, ص202 شعراً من احياء جده للمؤدة

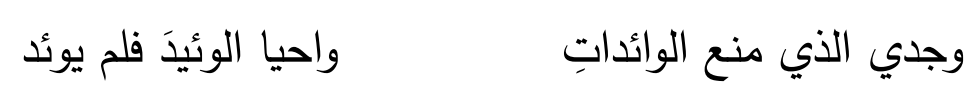

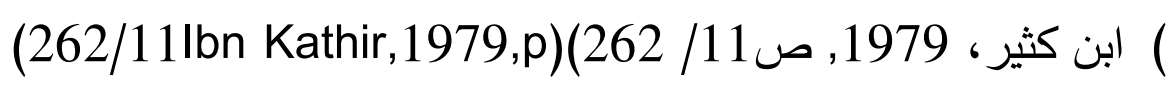

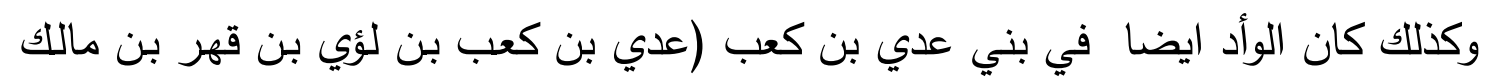

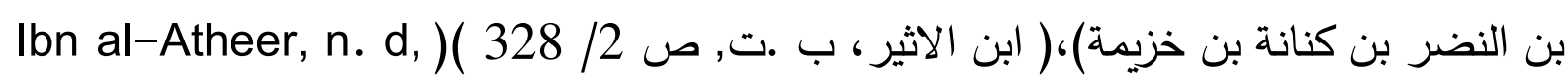

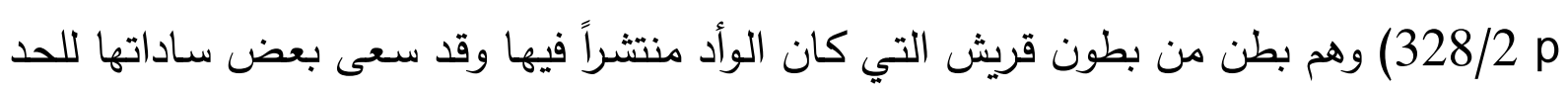

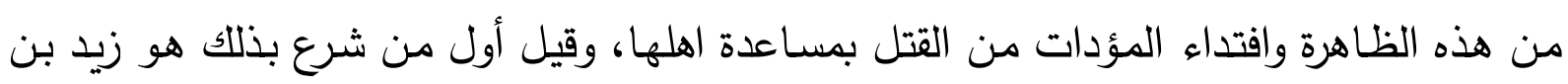

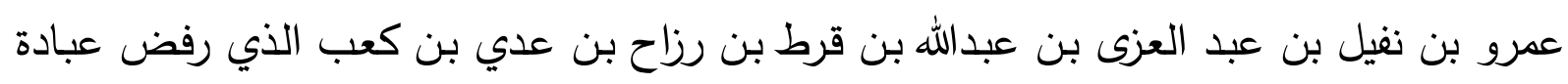

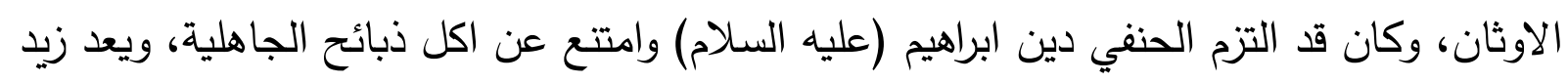

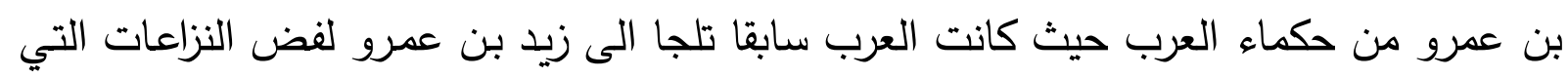

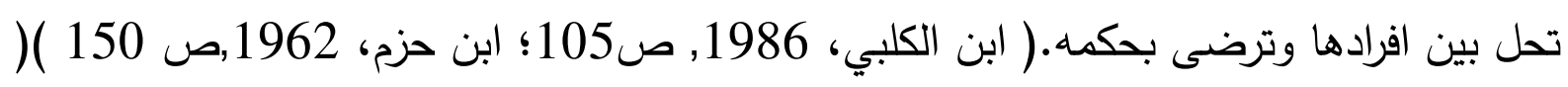
(150lbn al-Kalbi, 1986,p 105; lbn Hazm, 1962,p ظاهرة الوأد فكان يقول للرجل اذا اراد أن يقتل ابنتهُ: "لا تقلتها، اكفيك مؤنتها، فيأخذها، فإذا

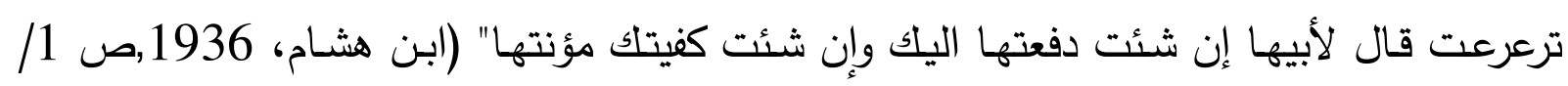
.(225/1 Ibn Hisham, 1936,p)( 225 ومن الذين كان يأد بناته الخليفة عمر بن الخطاب بن نفيل بن عبد العزى بن عبدالله بن قرط بن رزاح بن عدي بن كعب نشأ عمر بن الخطاب نشأة عربية وقد مارس التجارة وكان واحداً 
من الرجال الذين لعبوا دوراً في احداث مكة قبل اسلامه فقد كانت اليه السفارة وذلك أن قريش كان

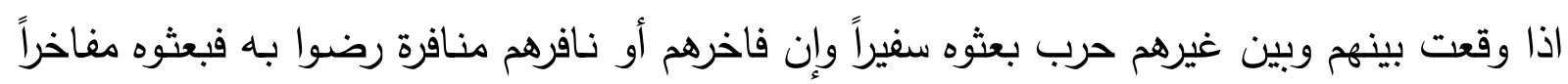

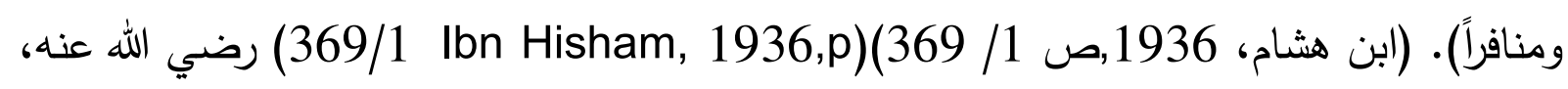
إلا أنه ندم على ذلك فقد سئل عن الوأد فأجاب: (كنا في الجاهلية لا نعد النساء شيئًا فلما جاء

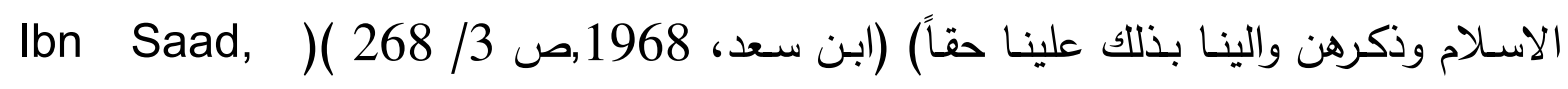

.(268/3 1968,p

وفي رواية اخرى: (و الله إنا كنا في الجاهلية ما نعد للنساء امراً حتى انزل الله فيهن ما انزل،

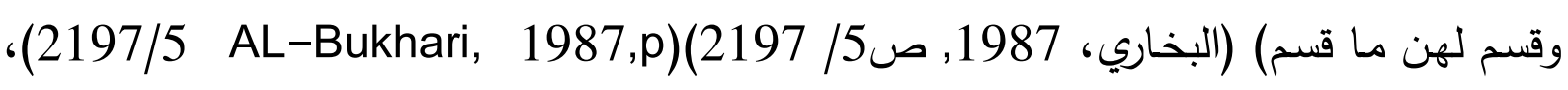

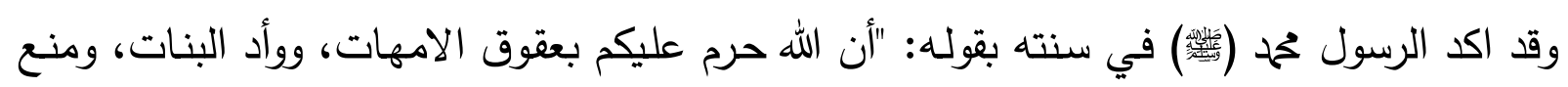

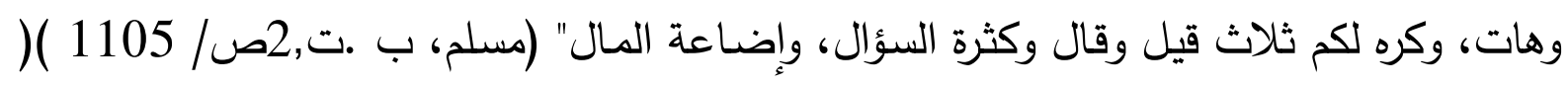
.(1105/2 Muslim,n.d,p لقد كانت ظاهرة تفضيل الذكر على الانثى سائدة قبل الاسلام ولا سيما في بيئة صحراوية

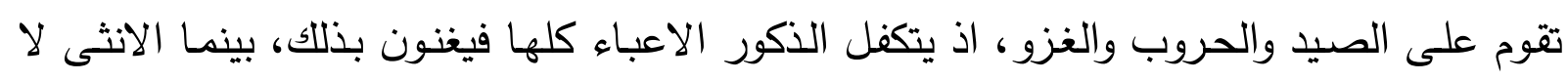

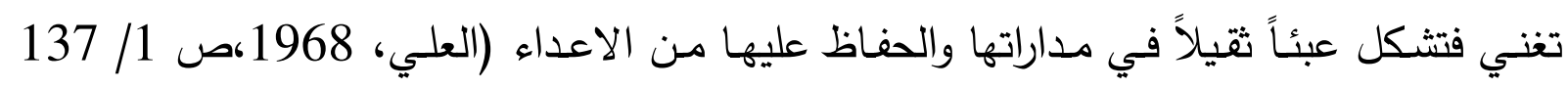
.(137/1 Al-Ali, 1968,p)(

لقد بلغ الحد بالبعض من الرجال أن يكره ولادة الانثى فيمتلى قلبهُ حزناً وغيظاً على زوجته

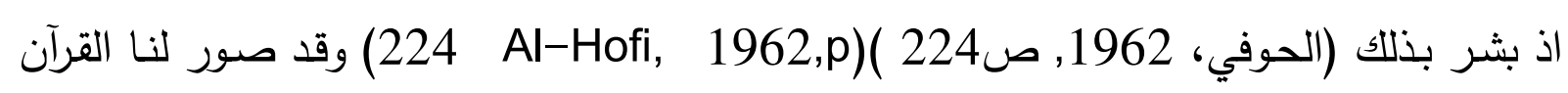

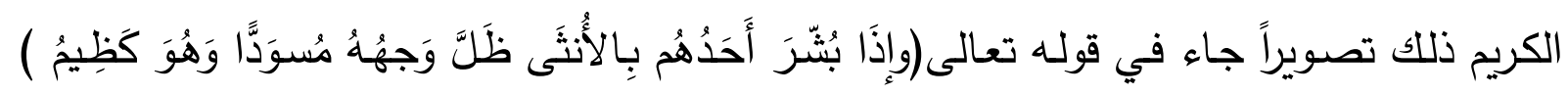

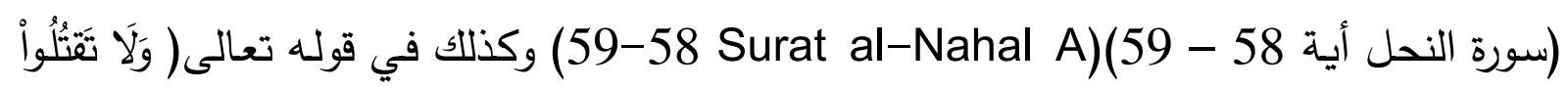

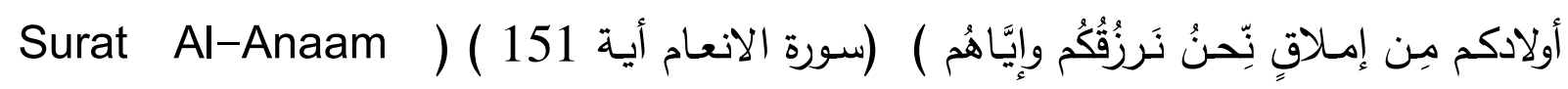

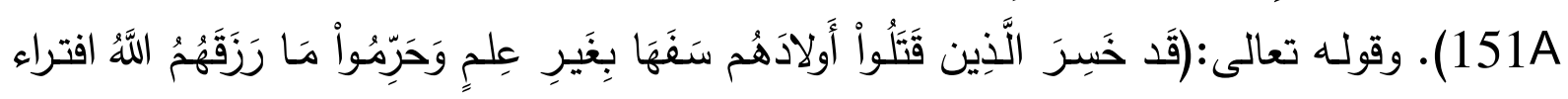

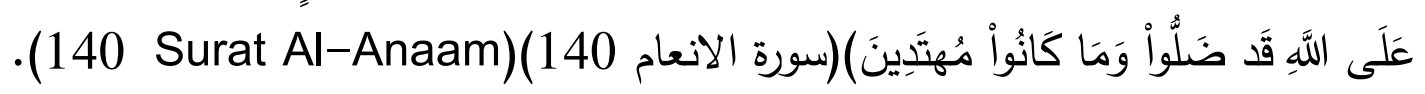
لقد كانت ولادة الذكر مبعث فرح وسرور في العائلة والقبيلة تلجأ إلى نحر الذبائح احتفالاً بمقدمسه ( ماجد، 1960,ص 11/53 Majid, 1960,p) (53/1). بعكس ولادة الانثى فكانوا

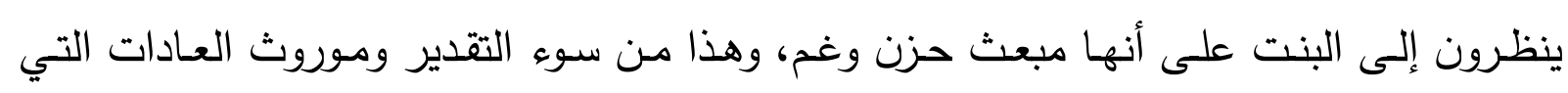
رفضها الاسلام (الابشهي، ب. ت, ص466 البه ) (466Al-abshi,n.d,p). 
وقد تسببت ولادة الانثى عند العرب الجاهلية من مفارقة الرجل لزوجتِه، فقد ذكر (الجاحظ,

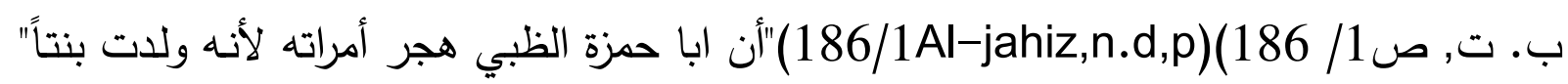
,

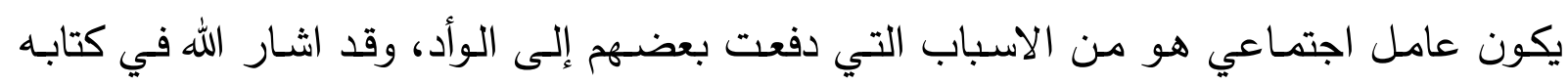

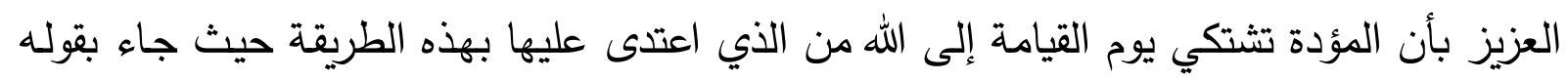

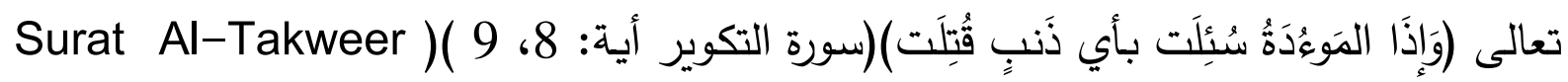

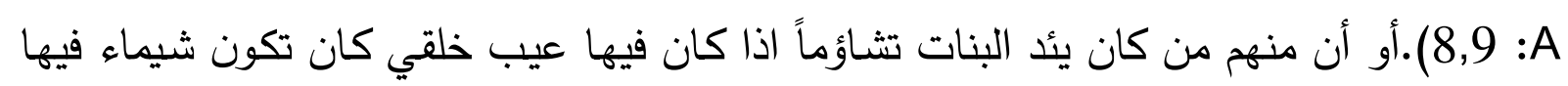

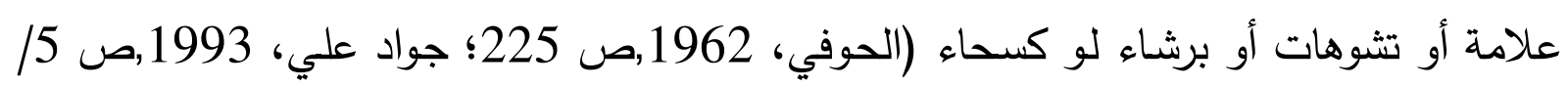

Al-Hofi, 1962,p 225; Jawad Ali, 1993,p 5/89).)(89

ومن خلال استعراضنا للوأد يمكن ان نلخص الاسباب التي دفعت بعض القبائل الى ذلك هو :

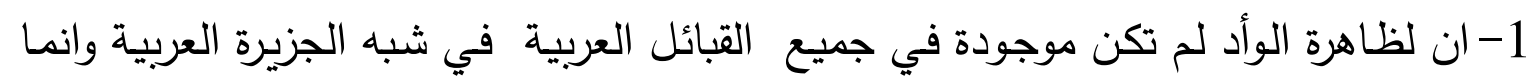

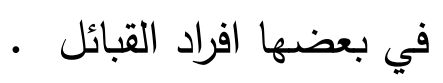

2- هناك الكثير من الظروف التي دفعت بعض افراد القبائل العربية للوأد كأن تكون اسباب اقتصادية كالعوز والفقر وسوء وضعها المعاشي ما تضطر الى ظاهرة الوأد. 3- او اسباب سياسية تتعلق بكثرة الحروب (الايام)حيث كانت تحدث الغارات على القبائل

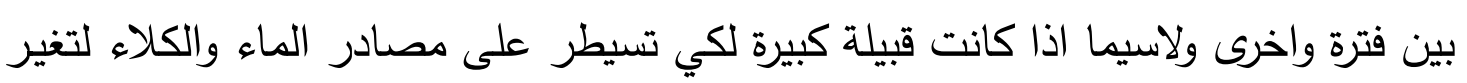

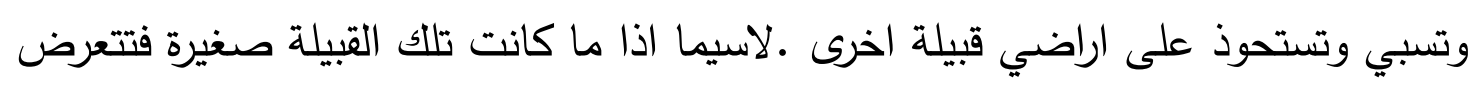

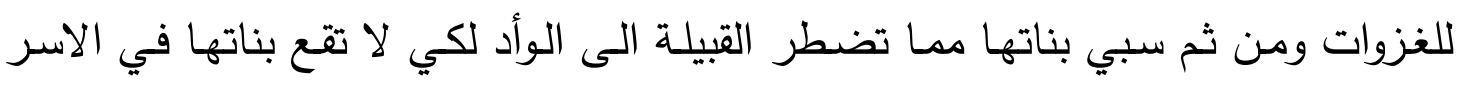

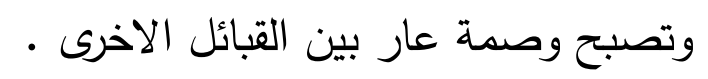

4-قد تكون الاسباب الاجتماعية واحدة من العوامل التي تدفع بعض القبائل إلى الوأد حيث التيث

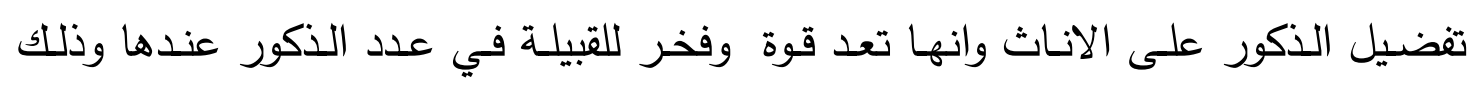

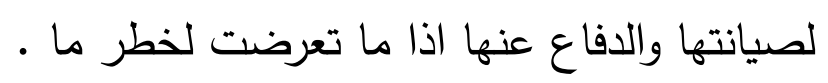
ثالثاً: انتساب الطفل الى الأم:

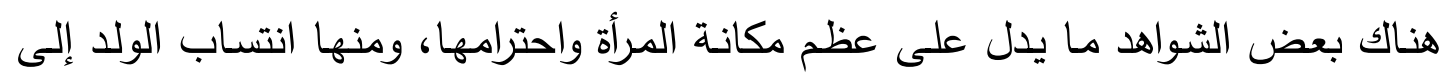
امه ومن الامثلة على ذلك : ولد الياس بن مضر بن نزار بن معد بن عدنان: عامر وهو مدركة، لهان

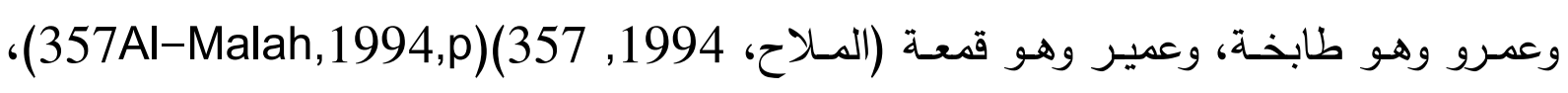
امهم خندف ( بنت حلوان بن عمران ابن الحاف بن قضاعة وأمها ضربة بنت رعبة ربيعة، وبها سمي 


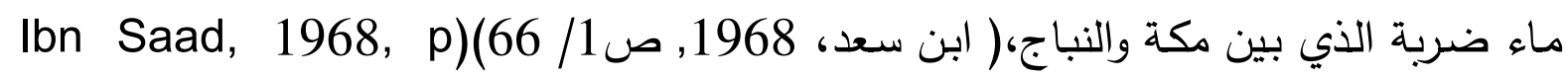

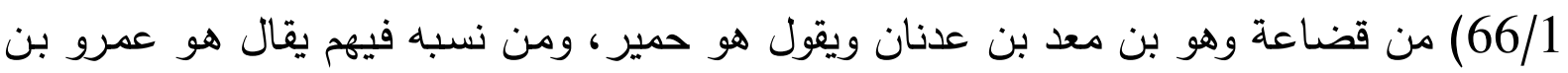

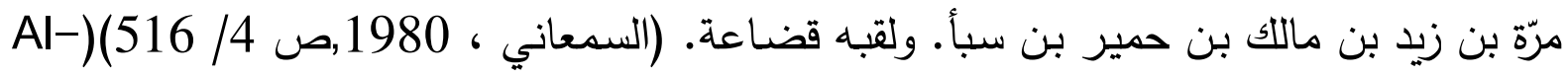
كزاف م16/4 Samani, 1980, p كذلك من الاولاد الذين نسبوا إلى امهاتهم لما لهم من كنايات وصفات خاصـة جعلت لهن صيتاً بعيداً مثل المنذر بن ماء السماء, وهو (المنذر بن امرئ القيس بن النعمان (الملقب بابن ماء

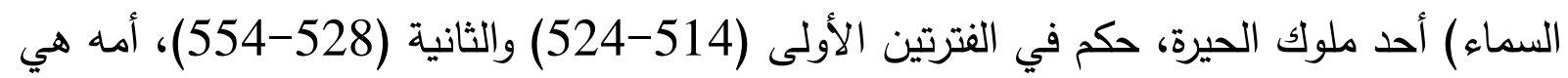
ماويـة بنت جشم وقد سميت بماء السماء لجمالها وحسنها، حكم المنذر مملكة واسعة اشتملت

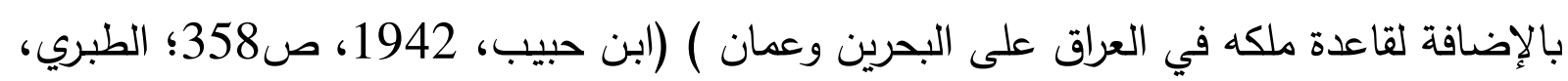

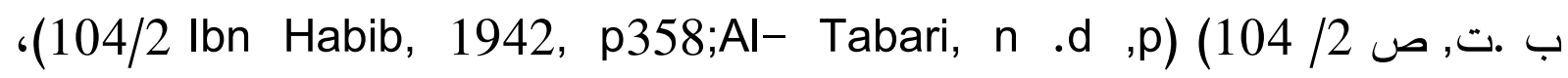
وكذللك عمرو بن هند (وهي هند بنت الحارث بن عمرو بن حجر بن آكل المرار ادركت ازواج

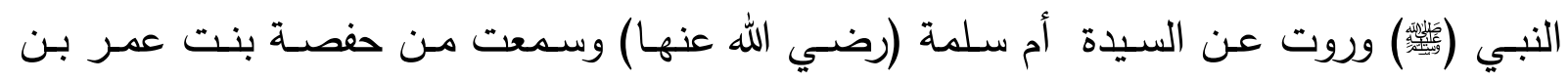

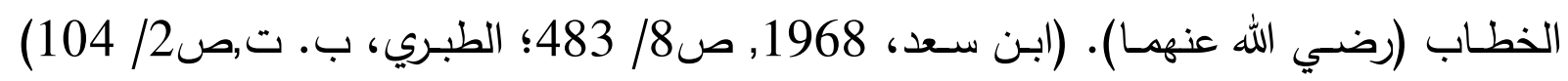
(104/2 Ibn Saad, 1968, p. 8/483; Al-Tabari,n.d, p)

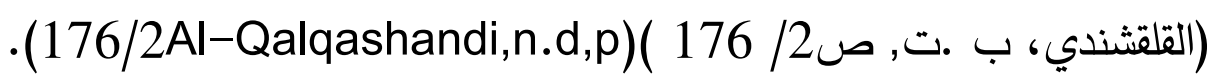
وقد افتخر العرب بنسبهم لأمهاتهم كافتخارهم بنسبهم لإبائهم على الرغم من أن الانتساب إلى (إنى

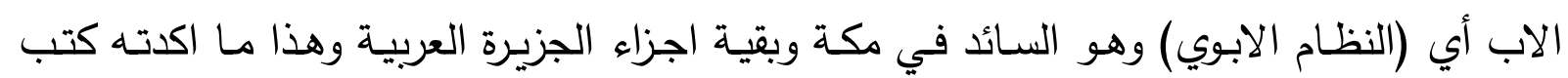

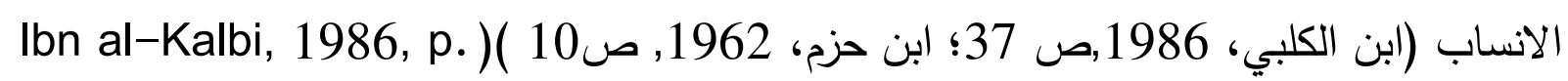
الأسياب (10.37; Ibn Hazm, 1962, p

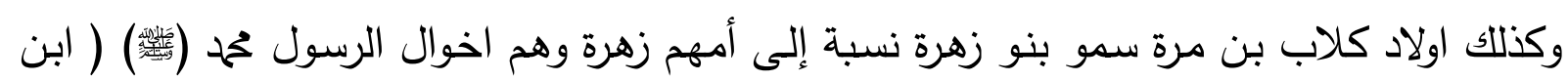

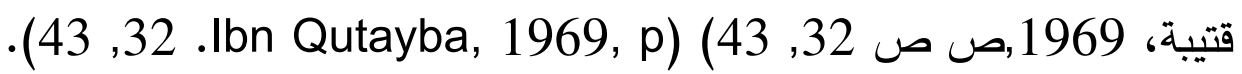
أما ابناء قبيلة عبد شمس بن عبد مناف (أمية الاصغر وعبد أمية ونوفل) ينطلق عليهم العبلات

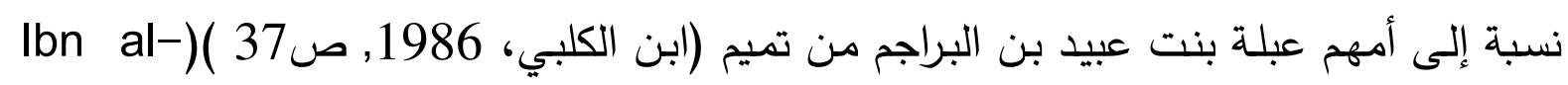
.(37 .Kalbi, 1986, p وكذلك ابن أم كلثوم وهو الاعمى الذي اشار اليه القرآن الكريم في سورة عبس وأم كلثوم هي

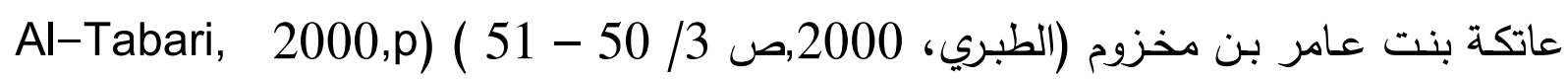
50/3-513) والثاعر السليك بن السلكة هو السليك بن عمير بن مقاعس بن عمرو بن كعب بن بن 
سعد بن زيد مناة بن تميم وهو ابن السلكة وهي أمسه وكانت سوداء وهو من فرسان العرب قبل

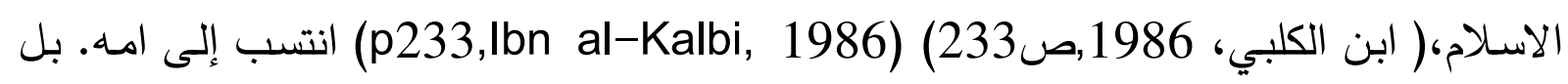

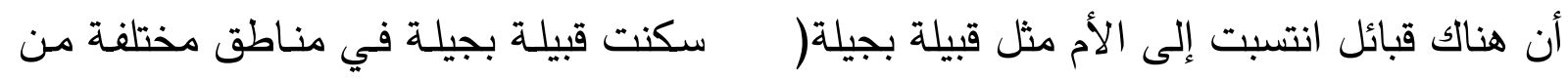

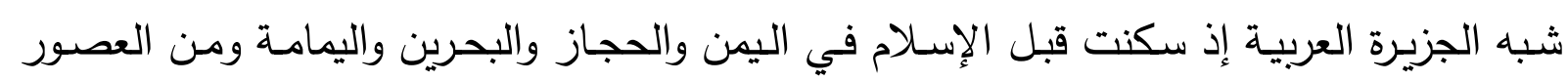

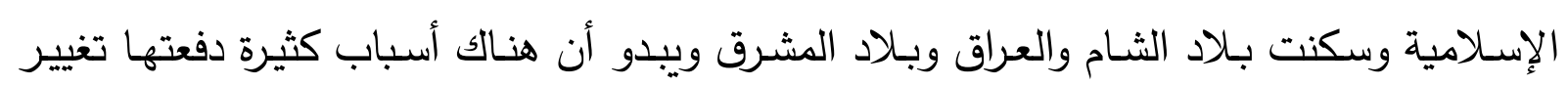

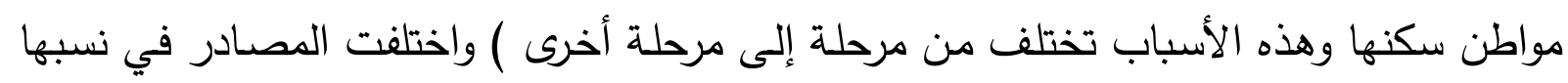

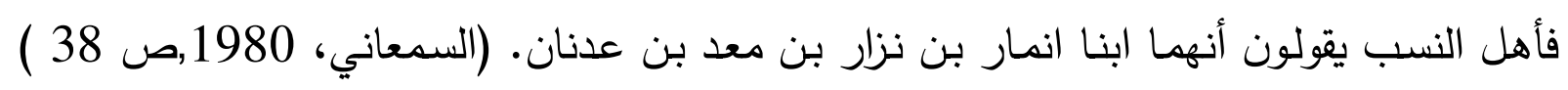
(38 . Al-Samani, 1980, p)

والبعض منهم من كان يكنى باسم ابنته وليس فقط الكنية باسم ابنه مثل الثـاعر المعروف

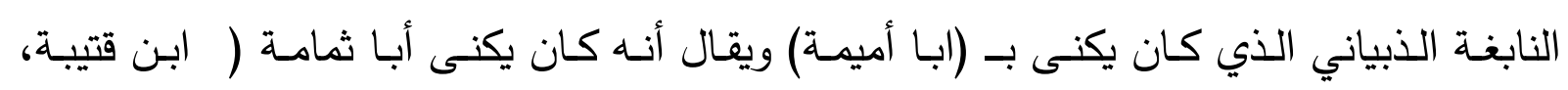

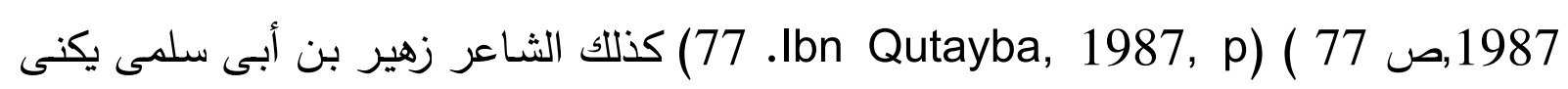

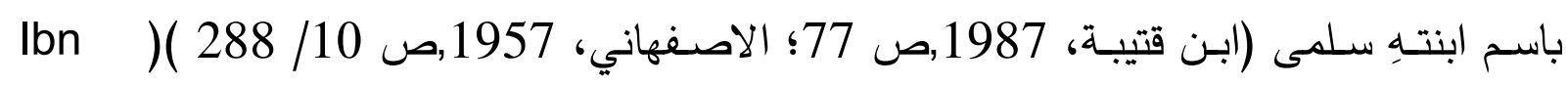
288/10 Qutaiba, 1987, p. 77;Al- asfahani, 1957,p

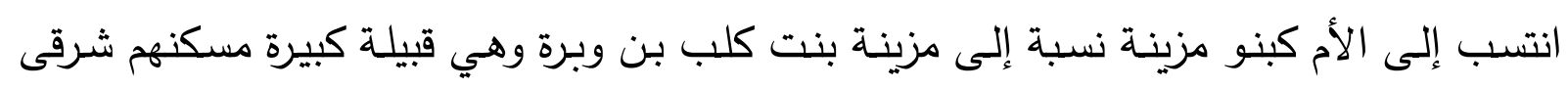

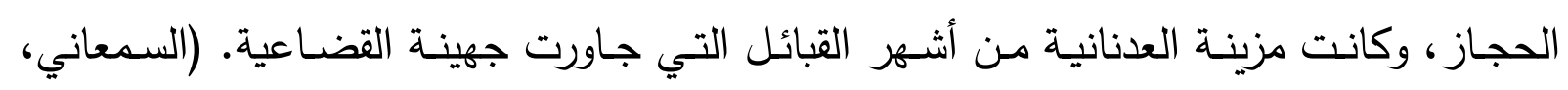

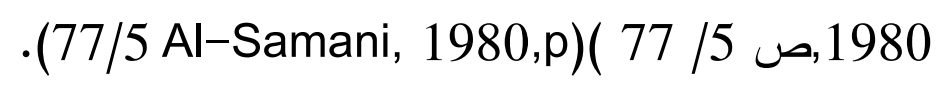

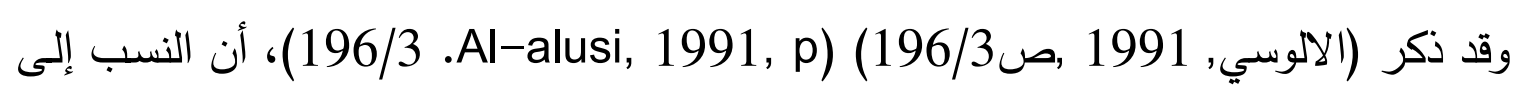

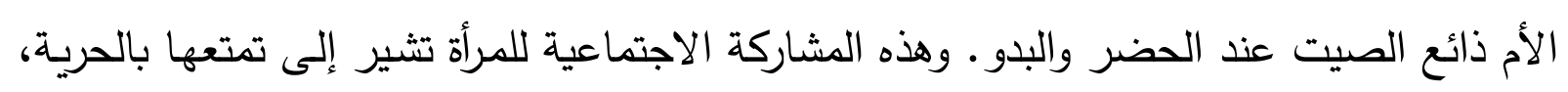

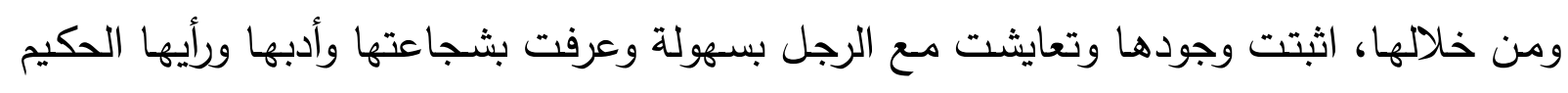

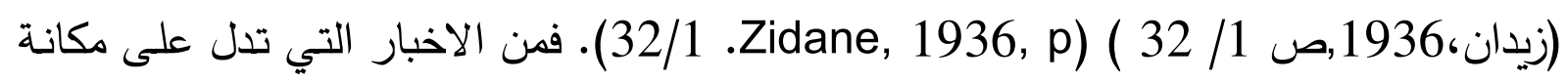
المرأة في الاسرة وحرص اهلها تزويجها من رجال اكفاء يحفظون لها ولأسرتها سمعتهم ومكانتهم.

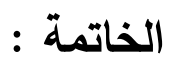

في ختام هذا البحث المتواضع وبفضل الله تعالى ثم التوصل إلى عدد من النتائج، وهي:

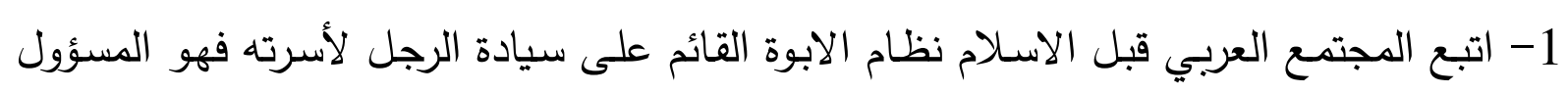
على تصريف امورها وحمايتها والمنظم لحياتها الاجتماعية والاقتصادية. 
2- كان للمرأة اثر مهم بالشكل الذي يناسب قدرتها وامكاناتها اذ لم يقتصر دورها على مهامها

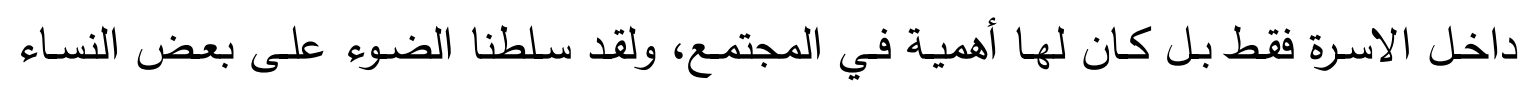
كزنوبيا ملكة تدمر والسيدة خديجة بنت خويلد التي كان لها دور في التجارة.

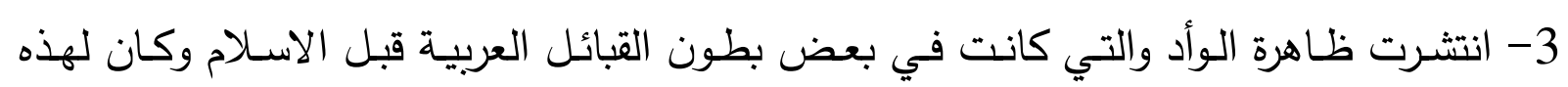
الظاهرة اسبابه السياسية والاقتصادية والاجتماعية، فعدت ظاهرة الوأد من الظواهر السلبية،

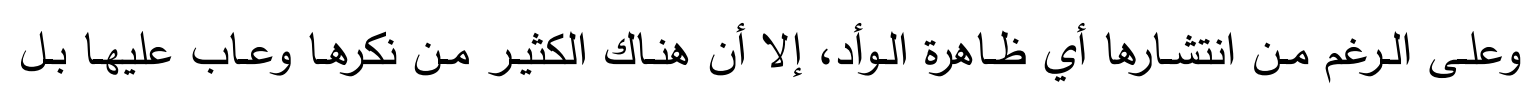
رفضها كعصعصه بن ناجية وزيد بن عمرو بن نفيل.

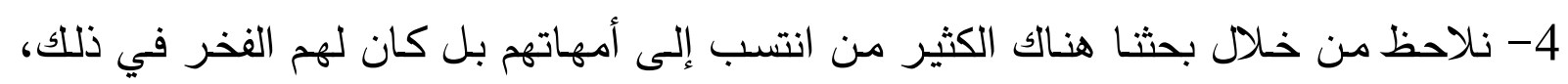

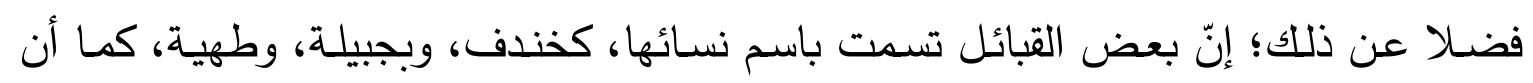

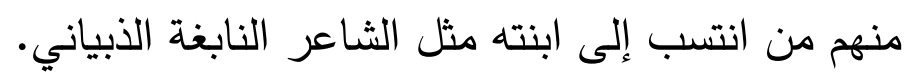

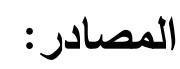
القران الكريم

ه الابثهي، ابو الفتح شهاب الدين محمد بن أحمد المحلي (850هـ/ 1446م) ، (ب ت).

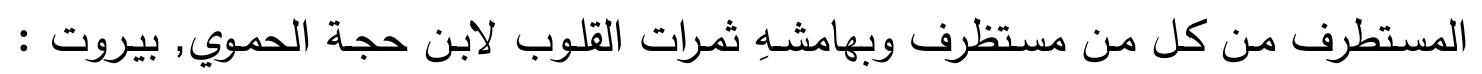
دار احياء التراث العربي. ابن الاثير، عز الدين ابو الحسن علي بن عبد الكريم بن عبد الواحد الثيباني الجزري

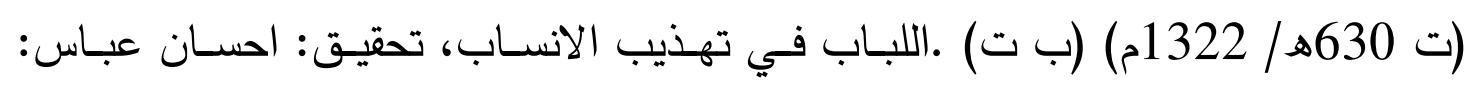
بغداد. مكتبة المثنى. •الاصفهاني، ابي الفرج علي بن الحسين (356هـ / 967م)(1957).(ب .ت). الاغاني , بيروت: دار الثقافة .

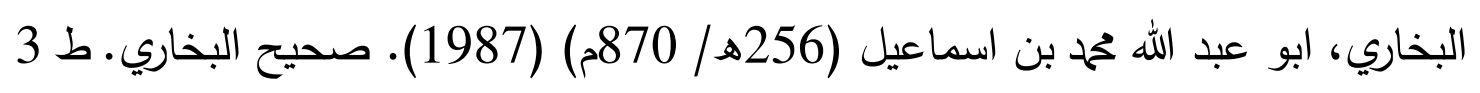
، تحقيق: مصطفى ديب البغا •بيروت: دار ابن كثير •

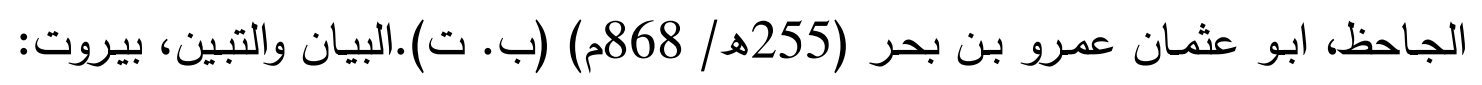
دار الكتب العلمية . •ابن الجوزي، عبد الرحمن بن علي (597هـ/ 1159م)(2004) ـاخبار النساء ,علق عليه وضبطه، بركات يوسف، صيدا / لبنان: المكتبة العصرية. 
•ابن حبيب، ابي جعفر محمد بن حبيب البغدادي (245هـ/ 859م) (ب .ت). المحبر ، رواية السكري، اعتنت بتصحيحه: اليزة لختن شتيتز • بيروت: دار الافاق الجديدة .

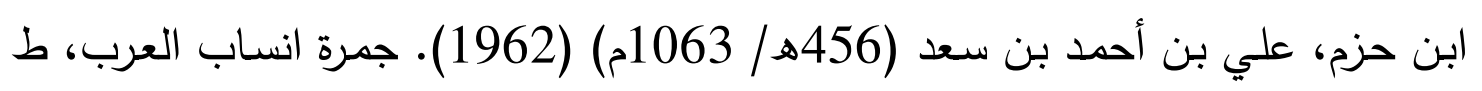

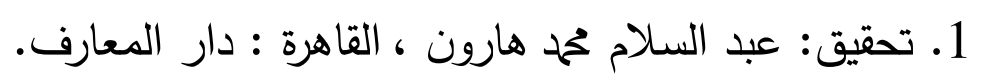

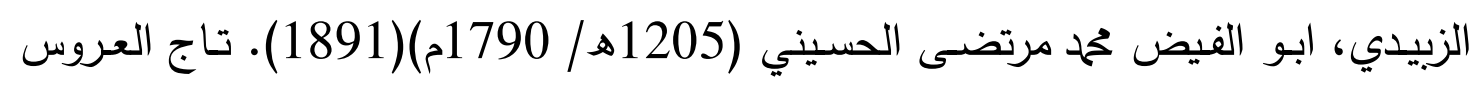
من جواهر القاموس. القاهرة : المطبعة الخيرية . هابن سعد, محمد بن منيع ( 230هـ/ 844م)(1968). الطبقات الكبرى، ط 1 ـبيروت: دار صادر السمعاني، ابو سعيد عبد الكريم بن منصور (562هـ/ 1166م)(1980) ـالانساب، ط 1. تحقيق: عبد الرحمن يحيى العلمي • بيروت.

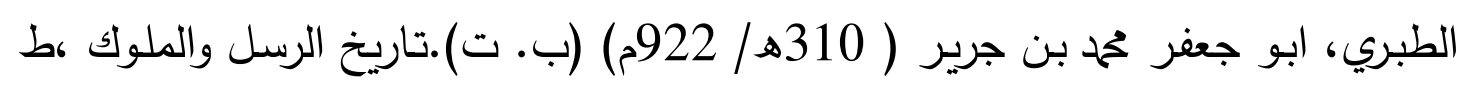

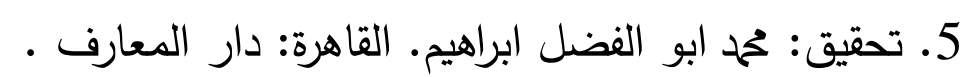
الطبري، ابو جعفر محمد بن جرير ( 310هـ/ 9229م) (2000,) .جامع البيان عن تأويل

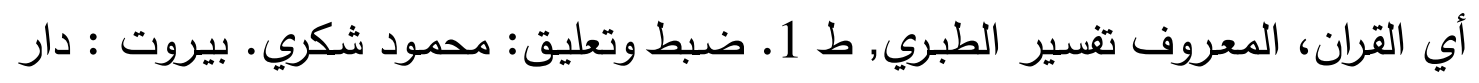

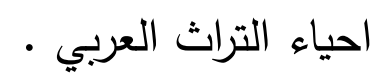

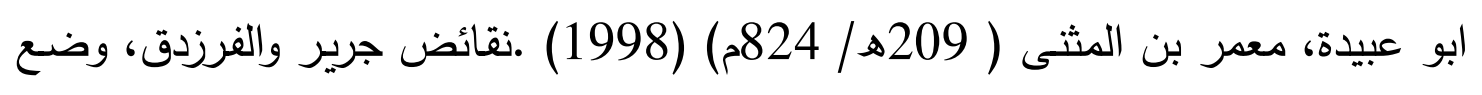
حواشيه: خليل عمران • بيروت: دار الكتب العلمية .

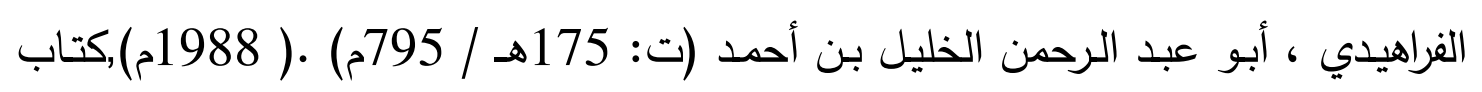

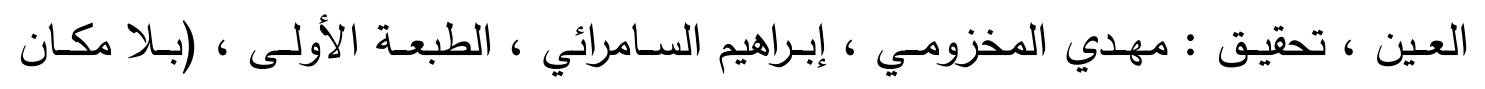

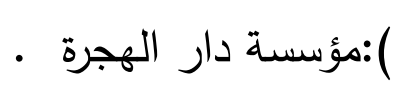

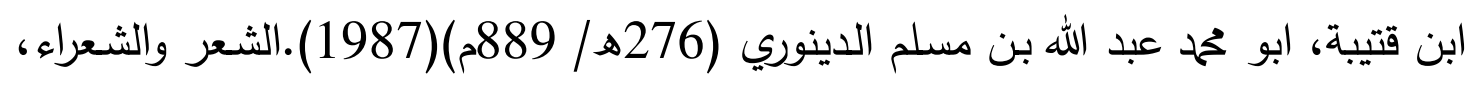

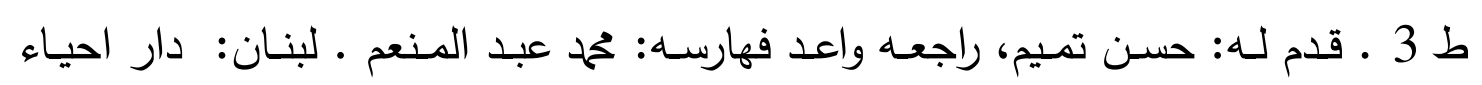
العلوم.

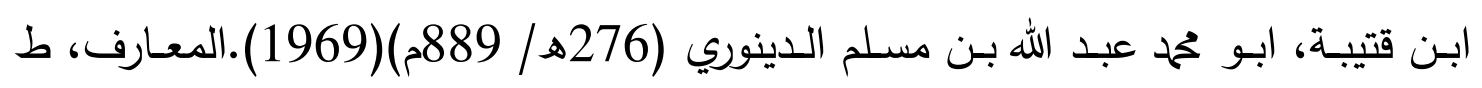

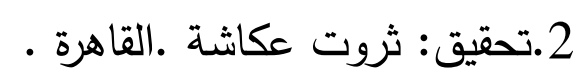

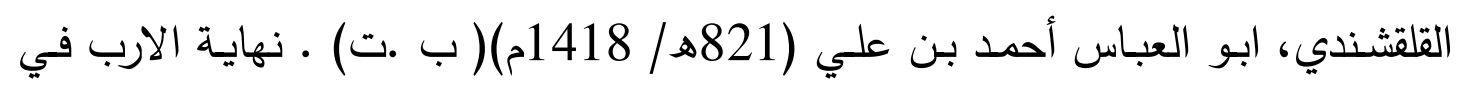

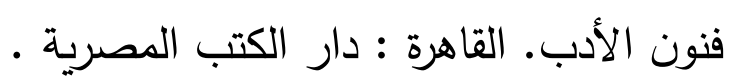




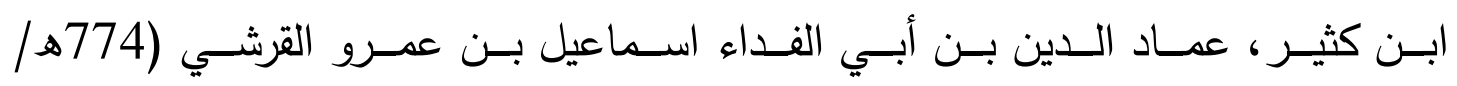

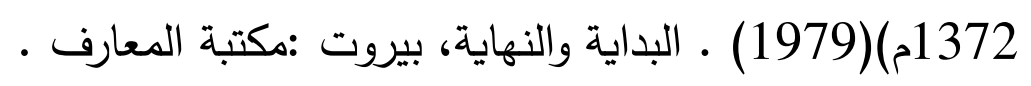

•ابن الكلبي، ابو المنذر هشام بن محم السائب (204هـ/ 819م) (1986) ـ ـ جمهرة النسب.

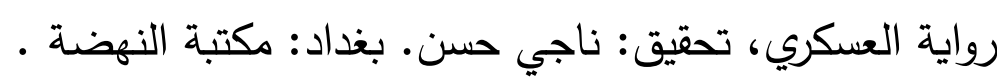

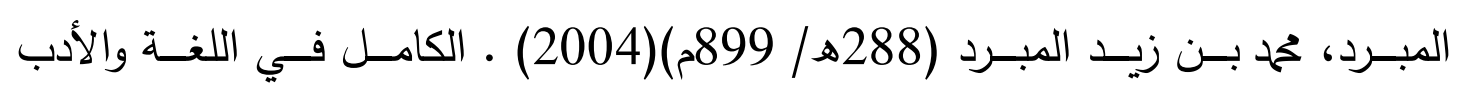
والتصريف، تحقيق: يحيى مراد. القاهرة : مؤسسة المختار .

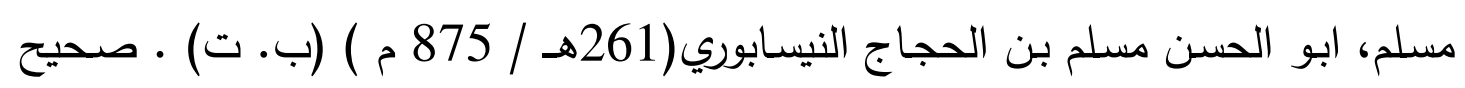

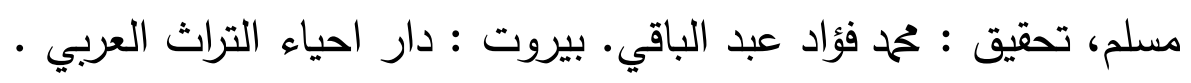

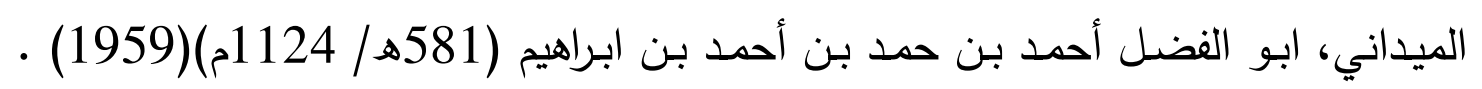
مجمع الامثال. تحقيق: محمد محي الدين عبد الحميد. مصر : مطبعة السعادة.

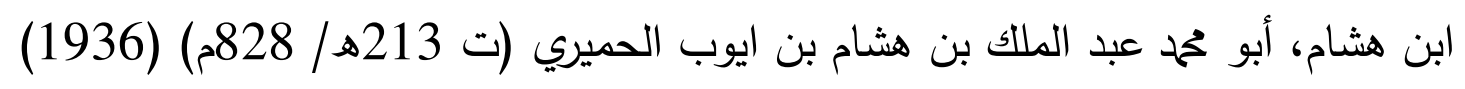

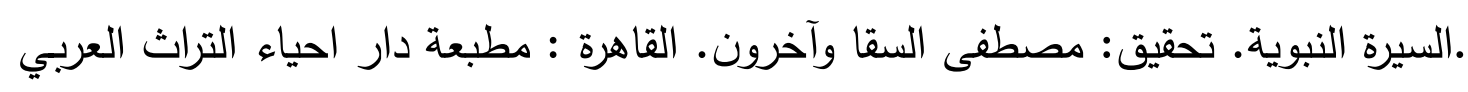
الألوسي، محمود شكري(1991) • بلوغ الارب في معرفة احوال العرب. شرحه وضبطهُ: محمد بهجة الأثري. بيروت : دار الكتب العلمية . جواد علي(1993) .المفصل في تاريخ العرب قبل الاسلام، ط 3. 3. جامعة بغداد. حسن، حسن ابراهيم(1996). تاريخ الاسلام السياسي والديني والثقافي والاجتماعي، ط لـ 4. بيروت : دار الجيل. هوفي، أحمد حمح (1962) ـ الحياة العربية من الشعر الجاهلي. بيروت: دار القلم .

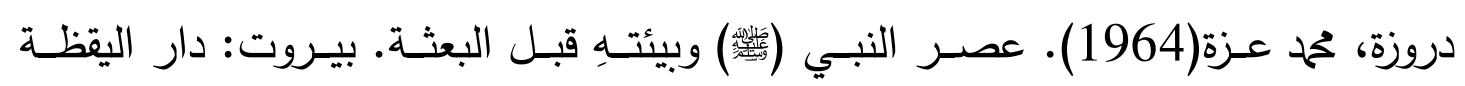
العربية.

زيدان، جرجي(1936). تاريخ أدب اللغة العربية، مطبعة الهلال.

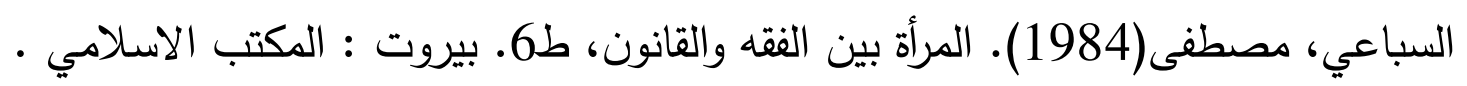

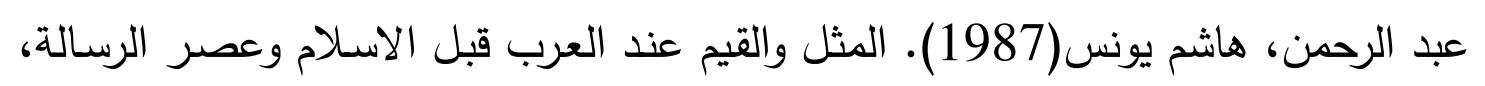
رسالة ماجستير، غير منشورة • جامعة الموصل , العراق.

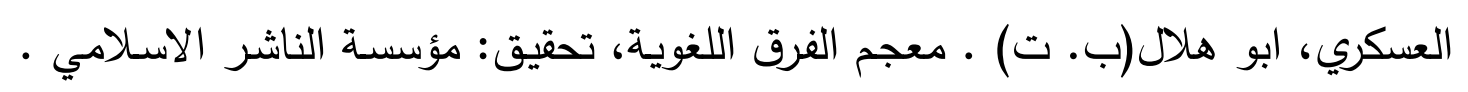

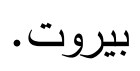


العلي، صالح أحمد(1968) ـ محاضرات في تاريخ العرب، ط 4. بغداد: مطبعة الرشاد

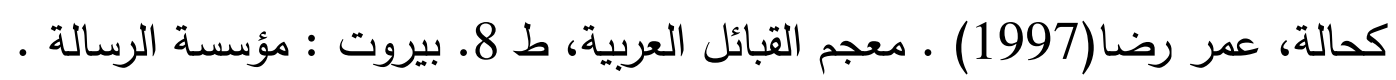

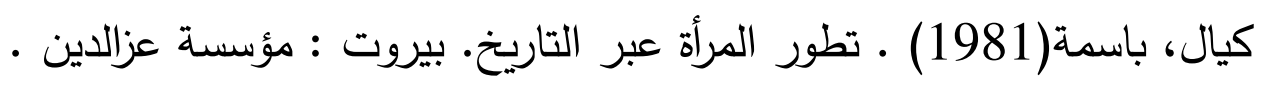

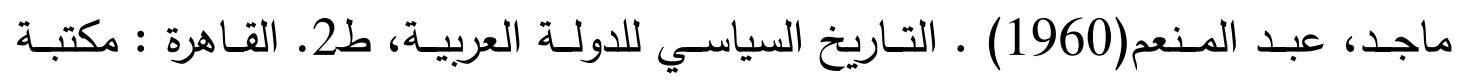
الانجلو المصرية .

المـلاح، هاشم يحيى(1994) ـ الوسيط في تاريخ العرب قبل الاسـلام. الموصل : دار الكتب للطباعة والنشر .

References

- Al-Abshahi, Abu al-Fath Shihab al-Din Mohammed bin Ahmed Almahali (850 Ah/ 1446AD), n.d. Almustatraf min kli mustadraf And by a margin Thamarat Alqulub to bin Hajjah al-Hamwi. Beirut Dar iihyaa alturath al-Arabiy .

- Ibn al-Atheer, Ezzedine Abu al-Hasan Ali bin Abdul Karim bin Abdul Wahid al-Shaybani al-Jazari (630 Ah/ 1322 A.D.) (n.d).Allubab fi tahdhib al-ansaab, Investigation: Ihsan Abbas, Baghdad: AlMuthanna Library.

- Al-Isfahani, Abi al-Faraj Ali bin Al-Hussein (356 Ah/ 967 AD) (1957). Al-aghany, Beirut. Dar Al- thaqafa.

- Al-Bukhari, Abu Abdullah Mohammed bin Ismail (256Ah/870 AD) (1987).Sahih Al- Bukhari, e d 3. investigation :Mustafa Deeb AlBaga ,Beirut :Dar Ibn Kathir. .

- Al-Jahiz, Abu Othman Amr bin Bahr (255H/868 AD) (n.d).Al-bayan waltabyin ,Beirut :Dar Al-kutub Al-eilmia .

- Ibn al-Jawzi, Abdul Rahman bin Ali (597 Ah/ 1159 AD) (2004). Akhbar Al-nisaa , Comment and Control, Barakat Youssef, Sidon / Lebanon: Modern Library.

- Ibn Habib, Abu Jaafar Muhammad bin Habib al-Baghdadi (245 Ah/ 859 AD) (n.d). Al-Muhbbir, the novel of Al-Sukkari, took care to correct it: Al-Yazza Lakhin Shtetr. Beirut: Dar Al-afaq Al-jadidah.. 
- Ibn Hizm, Ali bin Ahmed bin Saad (456 Ah/ 1063 AD) (1962).Jamharat ansab al-arab, d1. Investigation: Abdessalam Mohamed Haroun. Cairo: Dar Al-maearif.

Al- Zubeidi, Abu al-Al-Fayyad Muhammad Morteza al-Husseini (1205 Ah/ 1790 AD) .(1891)Taj Al-Eurus min Jawahir Al-Qamws. Cairo : Al-mutbaea Al-khayria

- Ibn Saad, Mohammed bin Mana'i (230 Ah/ 844 AD) (1968).AlTabaqat Al-kubraa, e d.1.Beirut: Dar Sader

- Al-Sa'amani, Abu Saeed Abdul Karim bin Mansour (562 Ah/ 1166 AD) (1980).Al-ansab ,e d1. Investigation: Abdul Rahman Yahya alAlami. Beirut. Al-Tabari, Abu Jaafar Muhammad bin Jarir (310 Ah/ 922 AD) (n.d).Tarikh Al- rusul Walmuluk, e d5. Investigation: Mohammed Abu Fadl Ibrahim. Cairo:Dar Al-maearif.

- Al-Tabari, Abu Jaafar Muhammad bin Jarir (310 Ah/922 AD) (2000), Jamie Al-bayan ean Tawil ayi Al-Quran, well- known Tafsir Al-Tabari, ed1. Tuning and commenting :Mahmoud Shukri. Beirut: Dar iihyaa Al-turath Al-earabi.

- Abu Obeida, Muammar bin Al- Muthanna (209 Ah/ 824 AD) (1998).Nuqayid Jarir wa Al-furazudq, Footnotes: Khalil Omran. Beirut: Dar Al-kutub Al-eilmia.

- Ibn Qutaiba, Abu Muhammad Abdullah bin Muslim al-Dinouri (276 Ah/ 889 AD) .(1987)Al-shier w Al-Al-shueara,ed3 .Presented to him: Hassan Tamim, reviewed and dated his indexes: Mohammed Abdel Moneim, Lebanon:Dar Iihyaa Al-eulum.

- Ibn Qutayba, Abu Muhammad Abdullah bin Muslim al-Dinouri (276 Ah/ 889 AD) (1969).Al-maearif,ed2. Investigation: Tharwat Okasha . Cairo.

- Al-Qasalshandi, Abu Abbas Ahmed bin Ali (821 Ah/ 1418 AD) (n.d).Nihayat Al-arbfi funun Al-adab. Cairo :Dar Al-kutub Al-misria.

- Ibn Kabir, Imad al-Din ibn Abi al-Fida Ismail bin Amr al-Qurashi (774 Ah/ 1372 AD) .(1979)Al-biddaya w Al-nihaya, Beirut: maearif Library. 
- Ibn al-Kalbi ,Abu al-Munther Hisham bin Mohammed al-Sa'ab (204 Ah/ 819 AD) (1986).Jamhart Al-nasab. Al-Askari's novel, Investigation: Naji Hassan. Baghdad: Al-nahda Library.

- Al-mubrad, Mohammed bin Zaid Al- mubrad (288Ah/899 AD) (2004).Al-kamil fi Al-lugha w Al-adab w Al-tasrif :,Investigation: Yahya Murad. Cairo: Al-Mukhtar Foundation.

- Muslim, Abu al-Hasan Muslim bin Al-Hajjaj Al-Nisaburi (261 Ah / 875 AD)(n.d). Sahih Muslim ,Investigation: Mohamed Fouad Abdel Baki. Beirut: Arab Heritage Revival House.

- Field, Abu fadl Ahmed bin Hamad bin Ahmed bin Ibrahim (581 Ah / 1124 AD) .(1959)Majmae Al-amthal .investigation :Mohamed Mohieddin Abdel Hamid. Egypt: Matbaeat Al-saeada.

- Ibn Hisham, Abu Muhammad Abd al-Malik bin Hisham bin Ayoub al-Hamri (213 Ah/828 AD) (1936).Al-syra Alnaubawia.Investigation :Mustafa Al-Sakka et al. Cairo: Dar iihyaa Al-turath Al-earabi

- Al-alusi, Mahmoud Shukri (1991).Bulugh Al-arb fi maerifat ahwal Al-earab. Explained and adjusted: Muhammad Bahja al-athary. Beirut :Dar Al-kutub Al-eilmia.

- Jawad Ali (1993).Al- mufassil fi tarikh Al-earab qabl Al-islam,ed3. University of Baghdad.

- Hassan, Hassan Ibrahim (1996). Tarikh Al-islam Al-siyasii waldinii walthaqafii walaijtimaii, ed4. Beirut :Dar al-Jil.

- Al-Hofi ,Ahmed Mohammed (1962).Al-hayat Al-earabia min Alshies Al-jahilii. Beirut: Dar al-Qalam

- Darwazeh, Mohammed Azza (1964) .Easr Al-nabi (salaa allah ealayh wasalam) wabiyatuh qabl al-bietha . Beirut:Dar Al-yaqda al-earabia.

- Zidan, Jerji.(1936) Tarikh adab al-lugha al-earabia,Matbaeat Alhilal.

- Al-Sibai, Mustafa (1984).Almaraa bayn Al-faqh walqanun,ed6. Beirut: Islamic Office.

- Abdul Rahman, Hashim Younis (1987). The Ideals and values of the Arabs before Islam and the era of the message. Unpublished M.A. thesis .Mosul University,Iraq 
- Al-Askari, Abu Hilal (n.d).Muejm Al-firaq Al-lughawia, Investigation: Islamic Publisher Foundation. Beirut.

- Al-Ali, Saleh Ahmed (1968). Muhadarat fi tarikh Al-earab, ed4. Baghdad: Matbieat Al-Rashad .

- Kahala , Omar Reda (1997). Mujm Al-qabayil Al-earabia , ed8. Beirut: Al-Resala Foundation

- Kial, Bassema (1981).Tatawur Al-marr eabr al-tarikh. Beirut: Ezzedine Foundation

- Majid, Abdel Moneim) 1960). Al-tarikh Al-siyasi lildawla Alearabia, ed2. Cairo: Anglo-Egyptian Library.

- Al-malah, Hashim Yahya (1994).Al-wasit fi tarikh Al-earab qabl Alislam. Mosul: Dar Al-kutub liltabaand

- Al-Farahidi, Abu Abdul Rahman al-Khalil bin Ahmed (T: 175 Ah / 795 AD). (1988), Al Ain Book, Investigation: Mehdi Makhzoumi, Ibrahim Al-Samarrai, First Edition, "Nowhere": Dar al-Hijra Foundation 